\title{
Partitioning Apomixis Components to Understand and Utilize Gametophytic Apomixis
}

\author{
Pankaj Kaushal ${ }^{1 *}$, Krishna K. Dwivedi ${ }^{2}$, Auji Radhakrishna ${ }^{2}$, Manoj K. Srivastava ${ }^{2}$, \\ Vinay Kumar' ${ }^{1}$ Ajoy Kumar Roy ${ }^{2}$ and Devendra R. Malaviya ${ }^{3}$ \\ ${ }^{1}$ ICAR-National Institute of Biotic Stress Management, Raipur, India, ${ }^{2}$ ICAR-Indian Grassland and Fodder Research Institute, \\ Jhansi, India, ${ }^{3}$ ICAR-Indian Institute of Sugarcane Research, Lucknow, India
}

OPEN ACCESS

Edited by:

Emidio Albertini,

University of Perugia, Italy

Reviewed by:

Joann Acciai Conner,

University of Georgia, United States

Ross Bicknell,

The New Zealand Institute for Plant \&

Food Research Ltd., New Zealand

Diego Carlos Zappacosta,

Universidad Nacional del Sur.

Argentina

*Correspondence:

Pankaj Kaushal

pkaushal70@gmail.com

Specialty section:

This article was submitted to

Plant Breeding,

a section of the journal

Frontiers in Plant Science

Received: 15 November 2018

Accepted: 18 February 2019

Published: 08 March 2019

Citation:

Kaushal P, Dwivedi KK,

Radhakrishna A, Srivastava MK,

Kumar V, Roy AK and Malaviya DR

(2019) Partitioning Apomixis

Components to Understand

and Utilize Gametophytic Apomixis.

Front. Plant Sci. 10:256

doi: 10.3389/fp/s.2019.00256
Apomixis is a method of reproduction to generate clonal seeds and offers tremendous potential to fix heterozygosity and hybrid vigor. The process of apomictic seed development is complex and comprises three distinct components, viz., apomeiosis (leading to formation of unreduced egg cell), parthenogenesis (development of embryo without fertilization) and functional endosperm development. Recently, in many crops, these three components are reported to be uncoupled leading to their partitioning. This review provides insight into the recent status of our understanding surrounding partitioning apomixis components in gametophytic apomictic plants and research avenues that it offers to help understand the biology of apomixis. Possible consequences leading to diversity in seed developmental pathways, resources to understand apomixis, inheritance and identification of candidate gene(s) for partitioned components, as well as contribution towards creation of variability are all discussed. The potential of Panicum maximum, an aposporous crop, is also discussed as a model crop to study partitioning principle and effects. Modifications in cytogenetic status, as well as endosperm imprinting effects arising due to partitioning effects, opens up new opportunities to understand and utilize apomixis components, especially towards synthesizing apomixis in crops.

Keywords: apomixis, apomeiosis, endosperm, Panicum maximum, parthenogenesis, partitioning

\section{INTRODUCTION}

\section{Overview of Apomixis Phenomenon: Genetics and Regulation}

Apomixis is a natural method of clonal reproduction through seeds, whereby the progeny is represented exactly by the maternal genotype (Asker and Jerling, 1992). This phenomenon has tremendous potential in agriculture by virtue of its capacity to fix heterozygosity and hybrid vigor (Sailer et al., 2016), it may equate an "Asexual revolution" (Calzada et al., 1996) and is proposed as a "next generation breeding technology" (Hand and Koltunow, 2014).

Apomixis is widespread in the plant kingdom and naturally occuring in 326 genera representing 78 families in Angiosperms, the majority belonging to Poaceae, Asteraceae and Rosaceae (Hojsgaard et al., 2014b). Apomixis may be of gametophytic or sporophytic origin based on the tissue involved in the formation of the female gametophyte. Gametophytic apomixis is represented by either diplospory or apospory, based on the origin of embryo-sacs (ES) in the ovule from 
megagametophyte or a nucellar cell, respectively (Nogler, 1984a; Asker and Jerling, 1992). When the mode of seed formation is exclusively through apomixis or sexual pathways, the plant is designated as obligate (apomictic or sexual, respectively). However, when both modes are represented in the same plant (co-exist in same ovule, or in different ovules of the same plant), it is regarded as facultative in reproduction.

The basic mechanism leading to the seed clonality relies on bypassing the two phases of variability generation, meiotic recombination and fertilization, during the seed formation, eventually resulting in seeds with copied maternal genotype. Meiosis is avoided (or eliminated/modified) via formation of apomeiotic embryo sacs (ES) while fertilization is bypassed via parthenogenetic development of the egg cell (Nogler, 1984a). Different modes of formation of apomeiotic ES to generate an unreduced egg cell have been widely discussed (Crane, 2001; Koltunow and Grossniklaus, 2003). Cyto-embryological and molecular processes were studied in model aposporous (e.g., Brachiaria, Pennisetum, Cenchrus, Hieracium, Paspalum, Poa, etc.) and diplosporous taxa (e.g., Erigeron, Taraxacum, Tripsacum, etc.), and important insights into the phenomenon have been presented (Grimanelli et al., 2001; Ozias-Akins and van Dijk, 2007; Pupilli and Barcaccia, 2012; Schmid et al., 2015; Schmidt et al., 2015; Hojsgaard, 2018).

The genetics of apomixis, as investigated in these model species, appeared broadly to be under the control of one or a few major dominant genes demonstrating Mendelian segregation (reviewed in Savidan, 2000; Ozias-Akins and van Dijk, 2007; Barcaccia and Albertini, 2013). In parallel, a Hybridizationderived Floral Asynchrony (HFA) hypothesis was also proposed advocating the apomictic phenotype as a result of asynchronous expression of duplicate genes controlling female gametophyte development (Carman, 1997).

Information on inheritance models, genetic recombination potentials, molecular markers and molecular mapping studies in gametophytic apomicts have been compiled in recent reviews (Ozias-Akins and van Dijk, 2007; Pupilli and Barcaccia, 2012; Barcaccia and Albertini, 2013; Hand and Koltunow, 2014; Brukhin, 2017; León-Martínez and Vielle-Calzada, 2019). In general, dominance, polyploidy, hybrid origin and suppressed recombination are common features related to apomixis in the majority of the apomictic species (Nogler, 1984a), e.g., Apospory Specific Genomic Region (ASGR) in Pennisetum spp. and Cenchrus ciliaris (Akiyama et al., 2005; Conner et al., 2008), Apomixis Controlling Locus (ACL) in Paspalum simplex (Calderini et al., 2006), Loss of Apomeiosis (LOA) in Hieracium subgenus Pilosella (Okada et al., 2011) and Apospory (Apo) locus in Panicum maximum (Ebina et al., 2005; Takahara et al., 2014).

Comparative gene expression studies including transcriptome analysis were conducted in many of these species and differentially expressed genes during different stages of apomictic and sexual seed formation were identified (reviewed in Brukhin, 2017; Conner and Ozias-Akins, 2017). Some candidate genes have been shortlisted as potential key genetic factors (Bicknell and Koltunow, 2004; Albertini et al., 2005; Laspina et al., 2008; Sharbel et al., 2010; Silveira et al., 2012; Okada et al., 2013).
Recent studies on gene expression network supported sexual and apomictic reproduction to be closely related developmental pathways. Apomixis is suggested to be a heterochronic phenotype which relies on deregulation of the timing of reproductive events (especially entry in apomeiosis/meiosis during ES development and parthenogenetic/zygotic embryogenesis), rather than on the alteration of a specific component of the reproductive pathway (Grimanelli et al., 2003; Tucker et al., 2003; Sharbel et al., 2010; Koltunow et al., 2011; Hojsgaard et al., 2012; Hojsgaard, 2018). The eventual expression of mode of reproduction is also believed to be regulated by modifiers, supernumerary chromatin and epigenetic modifications that may operate on account of hybridity and/or polyploidization (reviewed in Roche et al., 2001; Hand and Koltunow, 2014; Bocchini et al., 2018).

\section{Apomixis and Polyploidy}

One of the key features on apomixis expression is its close relationship with polyploidy. In general, most of the naturally occurring apomictic species are polyploids, whereby lower forms (generally diploids) are sexually reproducing (Nogler, 1984a; Carman, 1997). However, recent recovery of natural and experimental diploids expressing apomixis indicate that though affected by the change in ploidy, apomixis expression is not restricted to polyploids (Visser and Spies, 1994; Siena et al., 2008; Lovell et al., 2013; Noyes and Wagner, 2014; Hojsgaard et al., 2014a; Schinkel et al., 2016, 2017; Klatt et al., 2018a). Effect of ploidy on apomixis expression has been studied in different apomictic systems using ploidy level variations at inter- or intraspecific levels (Savidan, 2000). Artificial polyploidization was observed to enhance (Quarin and Hanna, 1980; Quarin et al., 2001; Nassar, 2006) or reduce (Asker, 1967, 1980) its expression. Within a ploidy level, genotypic effects were more profound than ploidy effects in expressing mode of reproduction in many species such as Poa pratensis, Boechera spp., Ranunculus kuepferi and Panicum maximum (Matzk et al., 2005; Voigt-Zielinski et al., 2012; Schinkel et al., 2016; Kaushal et al., 2018). Such reports have contrasted the belief of ploidy-rise being the most important driver of apomixis evolution (Carman, 1997). In-fact, importance of hybridity over polyploidy, in governing apomixis, has been recently demonstrated (Delgado et al., 2016; Barke et al., 2018).

\section{THE APOMIXIS COMPONENTS AND THEIR UNCOUPLING/PARTITIONING}

\section{Components of Apomixis}

Seeds of sexual origin generate from a meiotically derived ES, generally Polygonum-type (8-nucleated), containing a reduced egg cell $(1 n)$, which develops into an embryo $(2 n)$ after fertilization with a reduced male gamete $(1 n)$. Endosperm in such seeds is a triploid $(3 n)$ tissue which develops from fertilization of a male gamete $(1 n)$ with two fused polar nuclei $(1 n+1 n=2 n)$. This pathway of seed formation may be represented as meioticES:zygotic-embryogenesis:pseudogamous-endosperm. In contrast, a generalized model on seed development though gametophytic apomixis (apospory or diplospory) essentially contains three components: apomeiosis (leading to formation of unreduced 
embryo sac); parthenogenesis (development of embryo without fertilization); and functional endosperm development (autonomous or pseudogamous) (Nogler, 1984a). These three components are linked functionally to generate apomictic seeds. Apomeiosis leads to the formation of meiotically unreduced embryo-sacs that contain egg cell, and polar nucleus/nuclei with sporophytic chromosome number $(2 n)$. The $2 n$ egg cell then develops parthenogenetically $(2 n+0=2 n)$ to generate a $2 n$ embryo. Embryogenesis is followed with development of endosperm either through fertilization of unreduced polar nucleus/nuclei (pseudogamy) or without fertilization (autonomous). This pathway of apomictic seed formation is represented as apomeiosis:parthenogenesis:functional-endosperm development (Asker and Jerling, 1992). The biological functions of the individual components and the progression from one stage to the next is presently under intense investigations (Grimanelli, 2012; Schmidt et al., 2015; Mirzagadheri and Horandl, 2016; Bocchini et al., 2018; Juranic et al., 2018).

\section{Partitioning Apomixis Components: Principle and Consequences}

The apomixis components were believed to be strictly under control of "one major locus," eventually generating an apomictic phenotype, in the majority of the agamic species (Savidan, 2000; Ozias-Akins and van Dijk, 2007). Accordingly, breeding strategies and molecular studies were designed for cultivar development, understanding the mechanism, mutagenesis and traits-introgression from related wild species. Occasional deviations from expected phenotypic frequencies and ploidies were considered as spontaneous off-types (Muntzing and Muntzing, 1943; Asker, 1980; Nakagawa and Hanna, 1990; Berthaud, 2001; Caceres et al., 2001). However, recent studies supported the fact that at-least in some of the apomictic taxa (see subsequent sections), the three apomixis components viz. apomeiosis, parthenogenesis and functional endosperm development may be uncoupled (Barcaccia and Albertini, 2013). Contrary to the "one locus" theory, the partitioning principle suggests apomixis under the control of three distinct genetic determinants, each controlling an individual component, and recombination between them possible. These recombinants have been isolated phenotypically in many apomictic species and the molecular principles (molecular markers, structural and functional genomics) underlying the mechanism are being investigated (Noyes, 2006; Zavesky et al., 2007; Kaushal et al., 2008; Koltunow et al., 2011; Conner et al., 2013).

The uncoupling may lead to newer combinations of partitioned apomixis components during the seed development process. As stated earlier, generation of clonal embryos relies on operating the apomeiosis:parthenogenesis pathway $(2 n+0)$ and this functional linkage is necessary to maintain ploidy and clonality. However, as a consequence of uncoupling of apomixis components, the functional linkage between apomeiosis and parthenogenesis is lost, and thus apomeiotically derived unreduced egg cell $(2 n)$ loses the capacity of parthenogenesis and requires fertilization with male gamete $(1 n)$ for embryo development, eventually leading to the formation of a triploid embryo $(2 n+1 n=3 n)$. This recombined pathway may be represented as apomeiosis:zygotic-embryogenesis. Alternatively, in a typical sexually derived egg cell $(1 n)$, requirement of

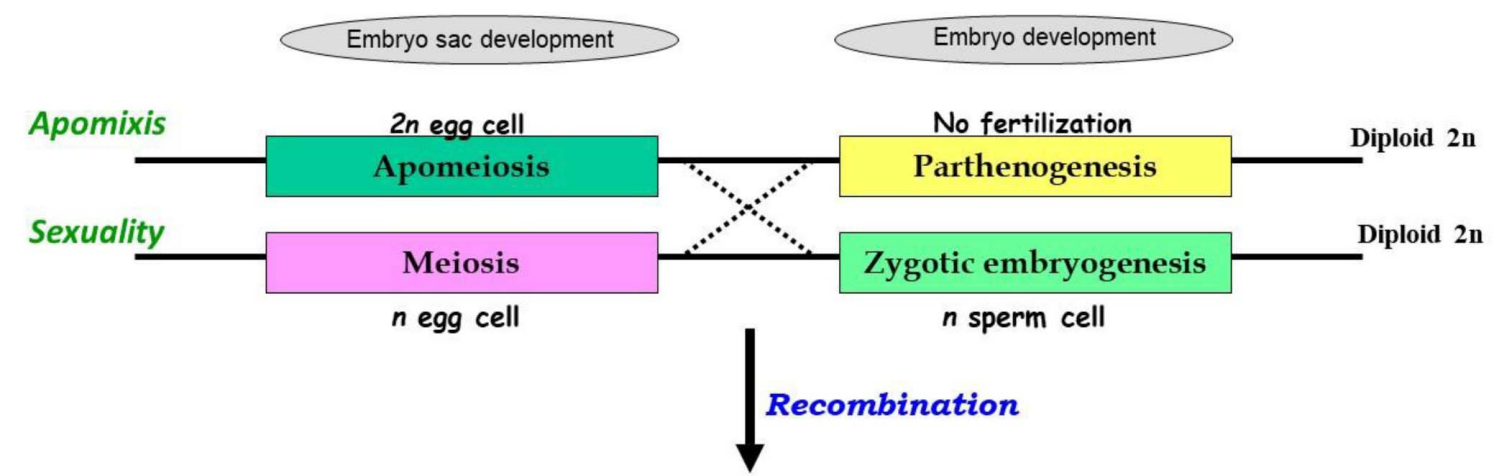

(2n)

(n)

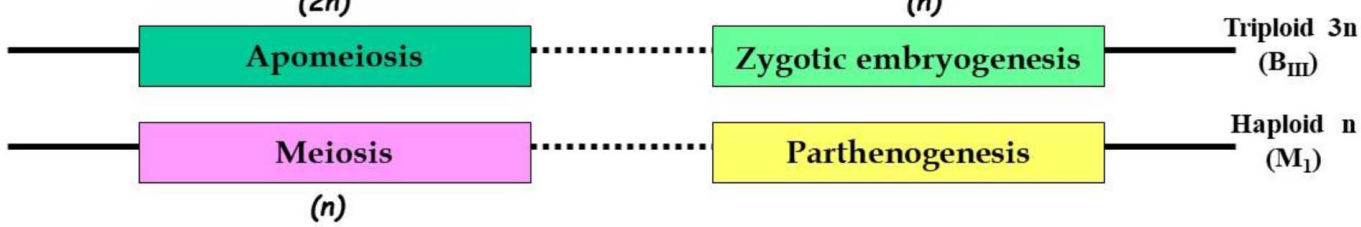

FIGURE 1 | Consequences of partitioning apomixis components leading to formation of triploids (3n) and haploids (1n) in the progeny of diploids (2n), through $B_{\| I}$ and $M_{1}$ pathways. Apomixis is achieved when an unreduced egg cell (in apomeiotic embryo-sac) develops through parthenogenesis, however, in sexually reproducing plants meiotically derived haploid egg cell fertilizes with a haploid sperm cell. In both cases, diploid status (2n) of embryo is conserved. In presence of genetic determinants for both these functions, as in heterozygotes, recombination between these elements may occur. Consequently, apomeiotic egg cell might require fertilization for embryo development leading to triploid $\left(2 n+n=3 n\right.$; $\left.\mathrm{B}_{\| I}\right)$ progeny. Alternatively, a meiotically derived haploid egg cell acquires the parthenogenetic capacity and develops without fertilization, leading to formation of haploid $\left(1 n+0=1 n ; \mathrm{M}_{1}\right)$ progeny. 
fertilization for embryo development is lost/replaced by parthenogenesis and the resultant embryo develops without fertilization yielding a haploid embryo $(1 n+0=1 n)$, following a meiosis:parthenogenesis pathway (Figure 1). Triploids derived through $2 n+n$ hybridization are termed as $\mathrm{B}_{\mathrm{III}}$ hybrids and the haploids $(1 n+0)$ as $\mathrm{M}_{1}$ plants (Rutishauser, 1948). Similarly, sexually derived diploids and obligate apomicts are designated as $\mathrm{M}_{\mathrm{II}}$ and $\mathrm{B}_{\mathrm{II}}$, respectively (Rutishauser, 1948; Aliyu et al., 2010). Broad categories of seed formation arising through partitioning events, in Polygonum-, Hieracium- and Panicum-type ES, is summarized in Table $\mathbf{1 .}$

Such partitioning events are largely believed to be consequence of recombination between apomixis components, however these are also influenced by modifiers and epialleles, and may show varied expressivity and penetrance (Noyes, 2006; Zavesky et al., 2007; Kaushal et al., 2008, 2018; Conner et al., 2013). This is expected in view of the suggested origin of apomixis via hybridization (maintaining a state of heterozygosity) (Nogler, 1984a; Carman, 1997; Talent, 2009). These "heterozygotes" may harbor genetic determinants for both apomixis and sexual reproduction and become amenable to uncoupling, owing to above mentioned factors. Similar heterozygous situation also prevails in progeny derived from experimental crosses between sexual $\times$ apomictic parents. As an illustration, haploid $\left(\mathrm{M}_{1}\right)$ progeny between sexual and apomictic parents in Potentilla collina was recovered through "parthenogenetic development of reduced ovules," whereby tendencies of formation of reduced gametes and the development of an egg cell without fertilization were derived from sexual and apomictic parent, respectively (Muntzing and Muntzing, 1943). Partitioning is also reported in experimental crosses between sexual and apomictic forms (intraas well as inter-specific hybridization) in Ranunculus, Panicum, Pennisetum, Cenchrus, and Poa (Savidan, 2000; Matzk et al., 2001, 2005; Ozias-Akins and van Dijk, 2007; Kaushal et al., 2008; Barcaccia and Albertini, 2013).

Similarly, for the third component of apomixis, viz., functional endosperm development, the mode of formation (pseudogamous or autonomous) may also get modified as a consequence of partitioning. For example, induction of autonomous mode of endosperm development in otherwise pseudogamous species by acquiring additional genetic determinants or by removal of suppressors that restrict the proliferation of polar nuclei in absence of fertilization, or vice versa. Such modifications are reported in several apomictic species (e.g., Taraxacum officinale, Panicum maximum, Hieracium spp., etc.) and in mutants mimicking apomixis components in otherwise sexual crops (van Dijk et al., 2003; Bicknell and Koltunow, 2004; Kaushal et al., 2008; Schmidt et al., 2015; Brukhin, 2017). During apomixis, although clonal embryos are generated from all categories of apomeiotic ES, the genomic ratios in endosperm largely depends on the developmental category of ES. For example, genome ratios (embryo:endosperm) in seeds derived from Polygonum- and Panicum-type ES are 2Em:3En, while it is 2Em:4En or 2Em:5En in Hieracium-type ES derived through autonomous or pseudogamous development, respectively (Table 1). Relative genome contribution of maternal and paternal genomes in embryo and endosperm constitution and the imprinting effects are thereby being studied to gain an insight into key genetic and epigenetic factors for successful endosperm development. Diversity in endosperm

TABLE 1 | Matrix showing possible categories of seeds and genomic contributions in three types of Embryo sacs (ES).

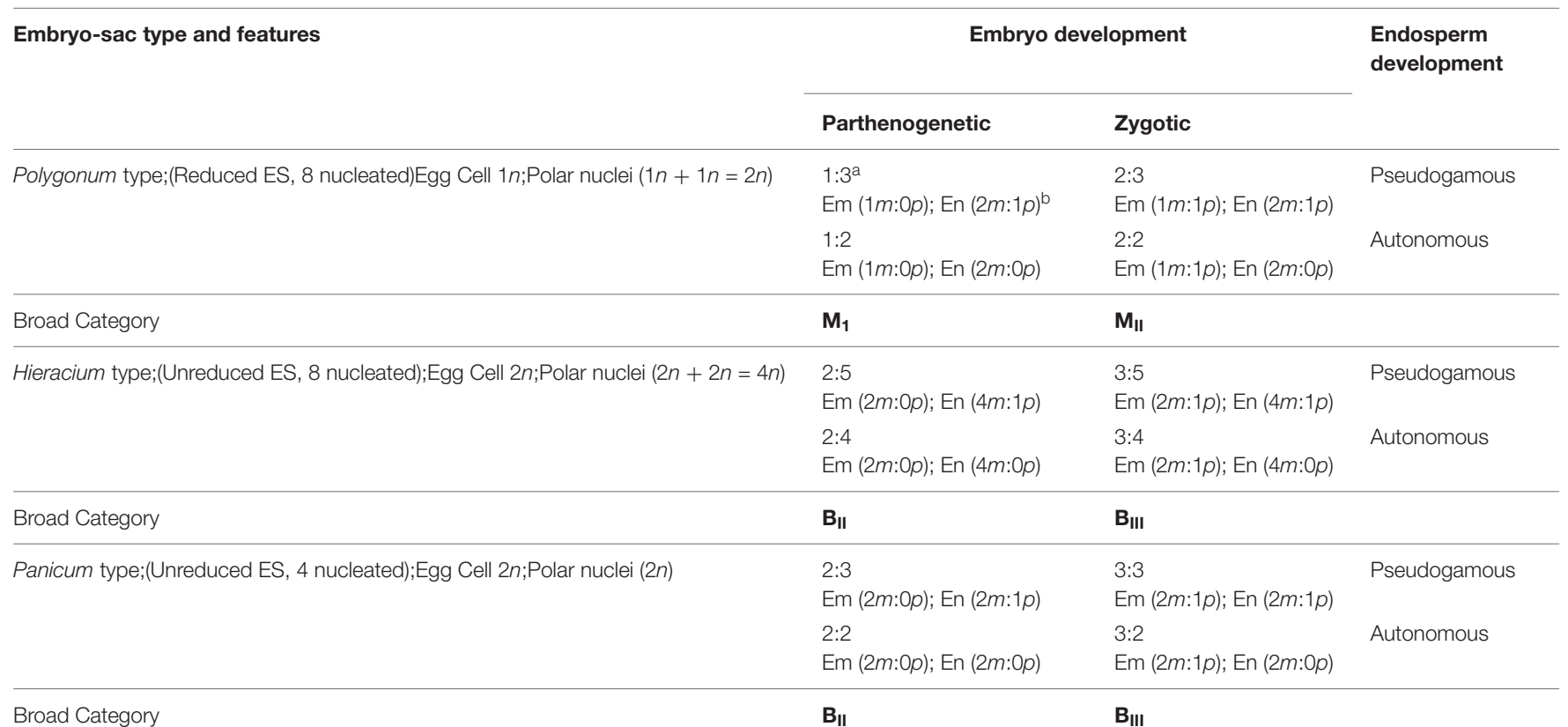

Genome constitution in embryo and endosperm are depicted from seeds originated from three types of ES (Polygonum-, Hieracium- and Panicum-type). Embryo

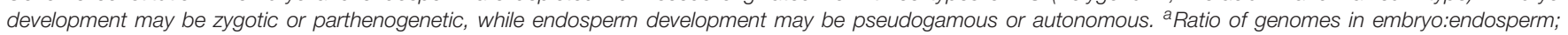
${ }^{b}$ Contribution of maternal ( $m$ ) and paternal genomes ( $p$ ) in embryo (Em) and endosperm (En). 
development, molecular mechanisms and the constraints of endosperm imprinting effects, are some of the issues of recent investigations (Pupilli and Barcaccia, 2012; Gehring and Satyaki, 2017; Henderson et al., 2017; Brauning et al., 2018; Depetris et al., 2018).

It would be interesting to debate whether apomeiosis and parthenogenesis have independent origins (Horandl, 2009; Talent, 2009; Tilquin and Kokko, 2016). In many taxa, the independent occurrence for capacity to generate unreduced gametes or haploid parthenogenesis suggest their independent origin during evolutionary lineage, however, their recurrent occurrence over generations will either polyploidize them out of existence or lead to haploid sterility. Interestingly, a combination of these two components stabilizes the system by maintaining the ploidy state, in spite of their individual capacities to modify it. From an evolutionary perspective, it seems logical that linkage between the apomixis components is essential for survival and perpetuation of the species to maintain the hybridity and ploidy, overcoming the constraints of genomic imbalances and ploidy levels of parental species. Species demonstrating partitioned apomixis components are regarded as evolutionary young apomicts, as compared to the species where recombination is suppressed (Pupilli and Barcaccia, 2012; Hand and Koltunow, 2014).
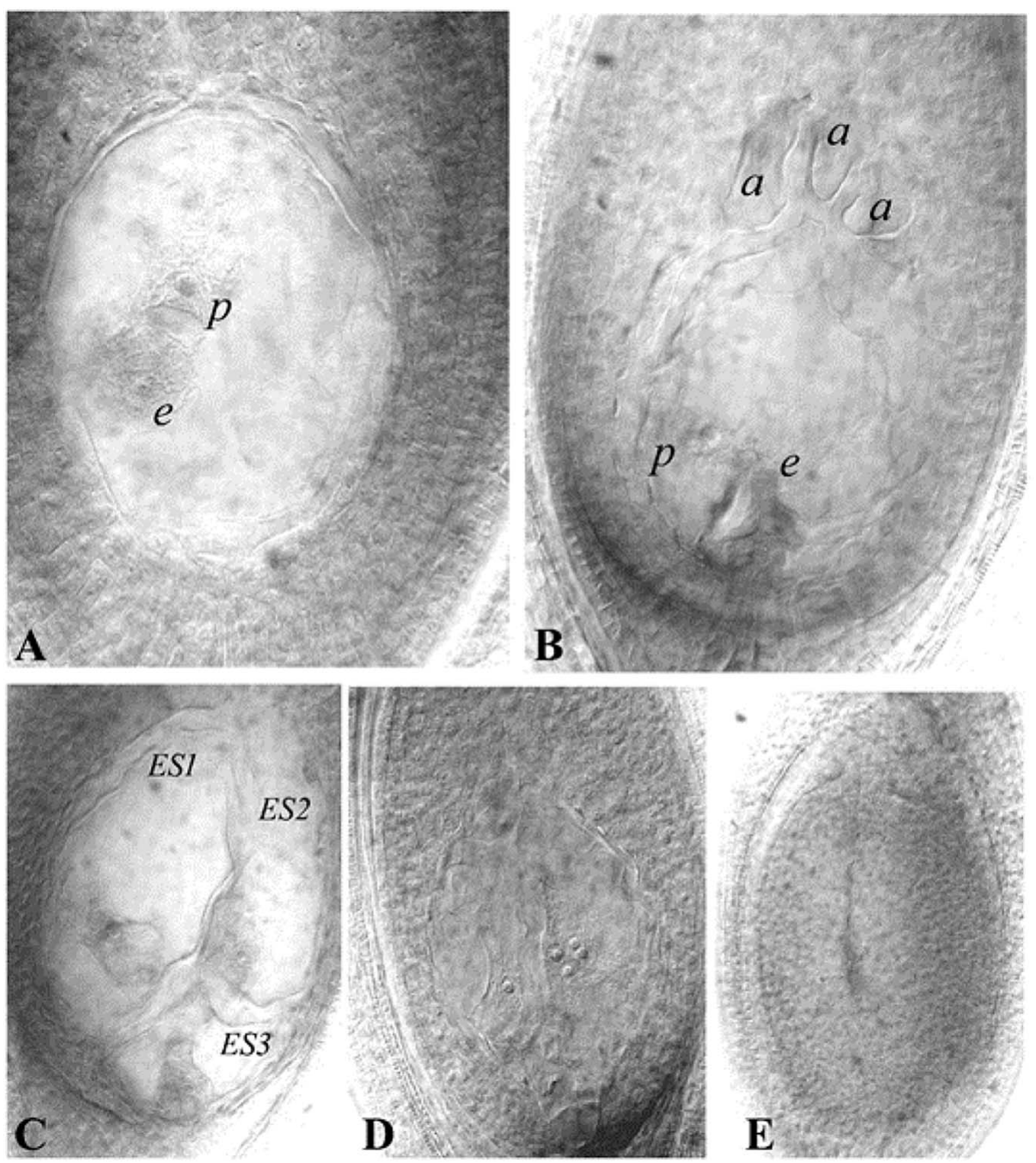

FIGURE 2 | Representative ES of guinea grass (cleared ovules). (A) Aposporous ES, (B) Sexual (or meiotic) ES, (C) Multiple ES (three ES seen), (D) Ovule showing proliferating polar nuclei in absence of pollination, as an indicator of AED, a cluster of four nuclei is visible in one plane, (E): Ovule showing an aborted ES. e- egg cell, p-polar nucleus, a- antipodals, ES-Embryo sac. Reprinted by permission from the Springer Nature: Kaushal et al. (2018). 
In a strict sense, the manifestation of sexuality might occur at two stages during seed development: the formation of meiotic (or sexual ES) which allows meiotic progression to generate variability in the gametes (in obligate sexual or facultative individuals), as well as during fertilization between male and female gametes (syngamy), irrespective of the meiotic or apomeiotic origin of the ES (yielding $\mathrm{B}_{\mathrm{II}} / \mathrm{M}_{\mathrm{II}}$ or $\mathrm{B}_{\mathrm{III}}$ hybrids, respectively). Interestingly, isolated apomixis components generate variability, and act as a driving force in evolving agamic species (Berthaud, 2001). The situation may be more complex in facultative individuals, as both sexual and apomeiotic factors are present in the same genotype, though with different extensions (Delgado et al., 2016; Kaushal et al., 2018).

\section{Detection Methods to Identify Partitioned Apomixis Components}

Modifications arising due to partitioning of apomixis components (ploidy of the progeny and mode of endosperm development) can be identified utilizing the characterization of embryo-sacs and ploidy estimation of the embryo of the progeny (Crane, 2001).

Histological differences between reduced (e.g., Polygonumtype: 8-nucleated sexual types) and unreduced ES (e.g., 4nucleated Panicum-type) have been utilized to characterize the presence of apomeiosis/meiosis. Methods to analyse ES structure development within the ovule have been modified from classical sectioning procedures to more rapid callose deposition tests (Peel et al., 1997; Tucker et al., 2001) and ovule clearing techniques (Young et al., 1979; Herr, 2000; Crane, 2001). Cleared ovules are now extensively utilized to characterize mode of ES formation, quantification of apospory and abortive ES, as well as to observe autonomous endosperm development (AED) (Figure 2).

The potential for parthenogenesis can be tested using "auxin test" (or auxin-induced parthenocarpy) (Matzk, 1991). Auxins replace the endosperm effect, thereby allowing initial development of embryo in the absence of endosperm, provided parthenogenesis genes are available. Auxin test has been successfully utilized to identify parthenogenesis potential in Poa spp., Hypericum spp., wheat-salmon system (Matzk et al., 2007) and Dichanthium annulatum (Gupta et al., 1999).

Triploids $\left(\mathrm{B}_{\mathrm{III}}\right)$ and haploids $\left(\mathrm{M}_{1}\right)$ were identified through classical chromosome-counting methods (Asker, 1980), and more recently using flow cytometric measurements of sporophytic DNA (Aliyu et al., 2010; Conner et al., 2013; Kaushal et al., 2018). The principle of flow cytometry was also utilized to develop a highly efficient and rapid screen, described as the Flow Cytometric Seed Screen (FCSS) (Matzk et al., 2000), which analyzes relative DNA contents of embryo and endosperm cells (from single/bulked matured seeds) to estimate their ploidies (Figure 3). When appropriately supplemented with information on the mode of ES development, ploidy of contributing male gametes (reduced/unreduced) and mode of endosperm development (autonomous/pseudogamous) can also be estimated, thereby enabling reconstruction of the possible reproductive pathways of seed formation. FCSS has been successfully implemented in confirming partitioning effects in diverse aposporouos and diplosporous apomicts, such as Brachiaria spp., C. ciliaris, Panicum maximum, Boechera spp., Hypericum spp., Poa spp., Tripsacum dactyloides, Hieracium spp., Paspalum simplex, Onosma spp., Rosa canina, Capsella bursa-pastoris, Crataegus spp., Ranunculus auricormus complex, etc., (reviewed in Krahulcova and Rotreklova, 2010; Kolarcik et al., 2018). FCSS also provides an opportunity (over progeny analysis) to analyze those proportions of seeds that might fail to germinate, owing to disturbed embryo:endosperm ratios, hence providing a better estimate of the partitioning events (Kaushal et al., 2008; Conner et al., 2013).

In addition to above analytical techniques, molecular markers tightly linked to individual components are also being utilized to identify partitioning events (see later sections for details on molecular markers) (Pupilli and Barcaccia, 2012; Barcaccia and Albertini, 2013; Conner et al., 2013; Hand and Koltunow, 2014; Brukhin, 2017).

\section{Partitioning Apomixis Components in Natural Apomictic Systems}

Genetic analysis and utilization of efficient screening techniques led to identification of apomictic species with possible recombination between apomixis components, both in aposporous apomicts such as R. auricormus (Nogler, 1984b), Poa pratensis (Albertini et al., 2001; Matzk et al., 2005), Hieracium spp. (Catanach et al., 2006), Panicum maximum (Kaushal et al., 2008) Hypericum perforatum (Matzk et al., 2001; Schallau et al., 2010), as well as diplosporous apomicts, such as Erigeron annus (Noyes and Rieseberg, 2000) and T. officinale (van Dijk and Bakx-Schotman, 2004) (reviewed in Krahulcova and Rotreklova, 2010; Pupilli and Barcaccia, 2012; Barcaccia and Albertini, 2013).

Cytogenetical and genetic mapping studies demonstrated the possibility and consequences of recombination between the apomixis components. It has been suggested that the recombination between apomeiosis and parthenogenesis (and/or functional endosperm development) may not be mutually exclusive, along with involvement of minor loci or modifiers in governing the phenotype (Barcaccia et al., 2006, 2007). As an illustration, in $H$. perforatum, most parthenogenetic plants were aposporic, however, several aposporic plants were nonparthenogenetic and recombinants for parthenogenesis were 10-folds higher than recombinants for apospory (Schallau et al., 2010). Similarly, in apomictic P. maximum germplasm accessions, parthenogenesis was uncoupled from apospory in about $26 \%$ of cases (Kaushal et al., 2008). Similar results were also reported in P. pratensis and H. perforatum (Matzk et al., 2001, 2005). However, there are a couple of reports on complete and independent expression of apomeiosis, including an apomeiotic non-parthenogenetic inter-specific hybrid between two sexual diploid species viz., Pennisetum glaucum and $P$. orientale (Kaushal et al., 2010), LOA and LOP mutants in Hieracium (Koltunow et al., 2011) and an ASGR recombinant in C. ciliaris (Conner et al., 2013).

As the expression of apomixis and its components is largely affected by genotype and hybridity, identification of 

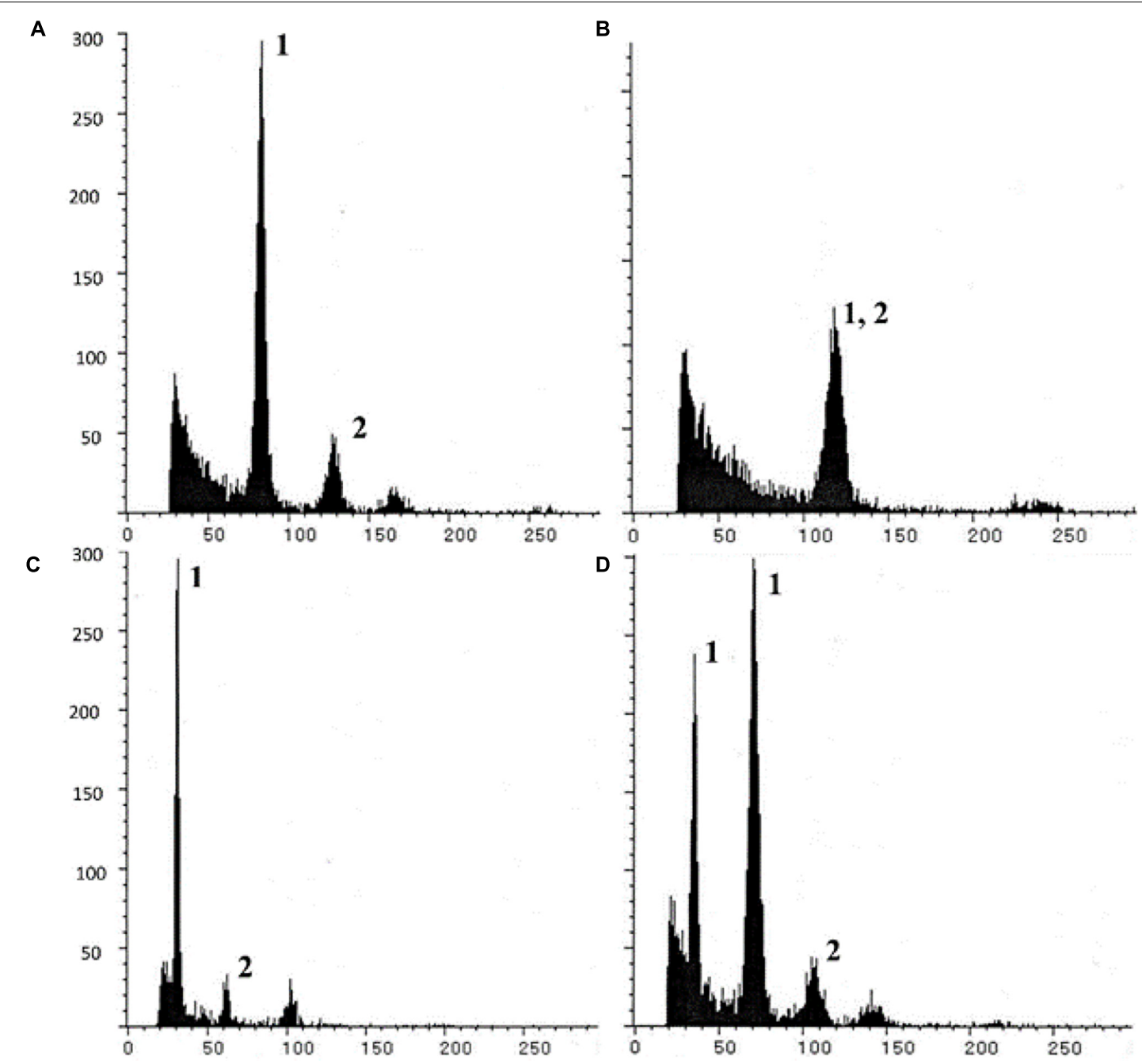

FIGURE 3 | Illustrative Single seed-FCSS histograms showing various progeny classes obtained in $P$. maximum, exhibiting (A) $2 n$ embryo (B $\mathrm{B}_{\| \mid}$or $\mathrm{M}_{1}$ origin; with

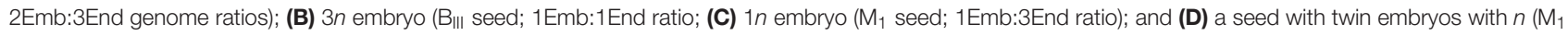
origin) and $2 n$ genomes and sharing common endosperm. In histogram, $x$ axis- relative fluorescence, $y$ axis- number of nuclei; Peaks 1 and 2 represent embryo and endosperm peaks, respectively, other unmarked peaks arise from endo-polyploidization events of embryo/endosperm cells. Reprinted by permission from the Springer Nature: Kaushal et al. (2018).

partitioning events relies on exploring sufficiently large and diverse germplasm collections, including (experimental) hybrids between sexual and apomictic parents. A survey of a sufficiently large germplasm base identified the occurrence of partitioning in P. pratensis (Matzk et al., 2005), H. perforatum (Matzk et al., 2001) and Pancium maximum (Kaushal et al., 2008), as also in experimental hybrids, e.g., in R. auricomus (Nogler, 1984b), P. collina (Muntzing and Muntzing, 1943), P. maximum (Kaushal et al., 2008) and C. ciliaris (Conner et al., 2013). Although in Paspalum, parthenogenesis and apospory were reported to be inherited together (Pupilli and Barcaccia, 2012), in intervarietal crosses between sexual and apomictic parents, $\mathrm{B}_{\mathrm{III}}$ hybrids were reported to occur (though in low frequency) in most of the apomictic progenies, and the uncoupling between apospory and parthenogenesis occurred among up to $50 \%$ cases (Caceres et al., 2001). Similarly, in P. maximum, wherein apomixis was believed to be monogenic (Savidan, 2000), uncoupling events were demonstrated in a wide scale screening of 669 genotypes (including a global germplasm collection), as well as in experimental hybrids (Kaushal et al., 2008, 2009). Recently, uncoupling of apomixis components has also been reported in $C$. ciliaris progenies obtained from sexual $\times$ apomictic lines utilizing FCSS and molecular markers analysis (Conner et al., 2013; Indian Grassland and Fodder Research Institute [IGFRI], 2013). These reports suggest that among many crops un-reported for partitioned apomixis components, a greater diversity in reproductive development regarding uncoupling of apomixis components is expected to be discovered by screening a larger and more diverse germplasm base, including the crosses between parents with contrasting reproductive capacities, and utilizing more efficient screening techniques. 


\section{GENETIC REGULATION OF PARTITIONED APOMIXIS COMPONENTS}

\section{Induction and Inheritance of Apomixis Components}

Experimentally, hybridization and polyploidy were attempted to test their potential to induce individual apomixis components, owing to the fact that these two are major contributory forces for origin of apomixis. Reports on de novo appearance of apomeiosis component through hybridization and/or polyploidization are more frequent, as compared to parthenogenesis and modification in endosperm development (reviewed in Mason and Pires, 2015; Kreiner et al., 2017).

From an apomixis perspective, induction of apomeiosis (apospory) has been reported as early as 1967 in certain hybrids of Sanguisorba (Nordborg, 1967) and in intergeneric hybrid Raphanobrassica (Ellerstrom and Zagorcheva, 1977; Asker, 1980). However, empirical results on the appearance of spontaneous apospory by inter-varietal or inter-specific hybridization between two sexually reproducing species, which eventually modified the mode of embryo-sac formation, have been recently reported in Pennisetum (Kaushal et al., 2010) and R. auricomus (Hojsgaard et al., 2014a). An interspecific hybrid $(2 n=16$, genome $G O)$ between two diploid and sexually reproducing species (Polygonum-type ES), viz. P. glaucum $(2 n=14 ; G G)$ and $P$. orientale $(2 n=18 ; O O)$, showed a transition from obligate sexuality (Polygonum-type ES) to apospory (>83\% Panicumtype aposporous ES). Parthenogenesis was completely omitted in this plant, and it produced all $\mathrm{B}_{\mathrm{III}}$ hybrids $(2 n=23$; GGO) when backcrossed with $P$. glaucum. The capacity for apomeiosis and zygotic embryogenesis was stable and inheritable in this hybrid, although a dosage effect was observed whereby upon adding sexual genome(s) from $P$. glaucum or apomictic genome from $P$. squamulatum, the expressivity of apospory was reduced or enhanced, respectively. The hybrid $(G O)$ also demonstrated de novo induction of AED (proliferation of polar nuclei), suggesting the induction of this component is also affected by hybridity. Similarly, sterility effects were overcome in interspecific and inter-ploidy crosses in Ranunculus by resorting to spontaneous apospory in mode of ES formation, eventually forming viable triploid seeds (Hojsgaard et al., 2014a). A novel phenomenon was also described for induction of apomeiosis through second division restitution in interspecific cross between Saccharum officinarum and S. spontaneum, whereby formation of a $2 n$ female gamete was triggered by the male gamete (Hermann et al., 2012). The induction is dependent on ploidy of $S$. sponateum as the male gamete in a dose-dependent manner and possesses the potential to be utilized for in vivo production of doubled haploids in intergeneric crosses. The induction of apomeiosis is known to be affected by hybridity and/or polyploidy, explainable on the basis of HFA theory (Carman, 1997) as well as epigenetic reprogramming of the genes involved in embryo-sac and endosperm development (Grimanelli, 2012; Kreiner et al., 2017; Hojsgaard, 2018).

Reports on induction of parthenogenesis through interspecific hybridization are rare, although inter- or intra-specific hybridization has been used to trigger haploidy via alternative pathways, such as uniparental genome elimination, utilizing genetic and cytogenetic stocks and alloplasmic cytoplasms (reviewed in Forster et al., 2007; Ishii et al., 2016). In apomictic systems, parthenogenesis component is generally contingent upon apospory or diplospory (Ozias-Akins and van Dijk, 2007). It is easier to partition it from apomeiosis, however, independent recurrent parthenogenesis is rarely naturally reported in plants, though it has been achieved experimentally (e.g., lop mutants in Hieracium; PsBBML in Pennisetum) (Koltunow et al., 2011; Conner et al., 2015; Mirzagadheri and Horandl, 2016).

Inheritance studies showed dominant inheritance of the partitioned apomixis components, however, with variable penetrance and expressivity, and were influenced by genotype and ploidy (reviewed in Ozias-Akins and van Dijk, 2007; Pupilli and Barcaccia, 2012; Barcaccia and Albertini, 2013; Hand and Koltunow, 2014). In $P$. pratensis, a multigene inheritance model has been proposed (Matzk et al., 2005), however, inheritance of parthenogenesis (PARTH1) as a dominant single gene was also proposed (Porceddu et al., 2002). Apomixis in T. officinale is under the control of two independent loci, one for diplospory $(D I P)$ and the another for parthenogenesis (PAR) (Vijverberg et al., 2004). Similarly, two independent dominant loci models have been proposed in diplosporous Erigeron annuus, one for diplospory $(D)$ and the other $(F)$ for both parthenogenesis and AED (Noyes et al., 2007). Three dominant loci, viz., LOA, LOP and AutE control individual apomixis components in Hieracium sugenus Pilosella (Koltunow et al., 2011; Henderson et al., 2017).

\section{Candidate Genes for Individual Components}

The fact that apomictic and sexual systems share a common network of gene actions during seed development (Hand and Koltunow, 2014), supplemented the efforts on identification of genes mimicking apomixis components in sexual systems. Mutants of these genes/genomic regions from sexual systems have been identified to exhibit apomixis components, and those involved in essential functions during megasporogenesis, meiosis initiation and progression, megagametogenesis, embryogenesis and endosperm development (e.g., DYAD, SWI1, Elongate1, SERK, ARG, MiMe sets, AGO, DMT, hap, BBM, FIE, MEA, $D M E$, etc.) (reviewed in Pupilli and Barcaccia, 2012; Barcaccia and Albertini, 2013; Schmidt et al., 2015; Brukhin, 2017). Transcriptome analysis involving ovular tissues during apomixis or sexual process have been compared in aposporous apomicts (e.g., Brachiaria brizantha, Pennisetum interspecific hybrids, C. ciliaris, $P$. maximum, Paspalum notatum, $H$. perforatum) and diplosporous apomicts (e.g., Boechera), and differentially expressed genes were identified (Reviewed in Conner and OziasAkins, 2017).

Additionally, detailed molecular analysis of genomic regions governing apomixis in natural apomictic systems led to the identification, characterization and isolation (in several cases) of key genes involved in apomictic reproduction per se or its components. These include genes controlling apomeiosis, such as APOLLO (Apomixis linked locus; Boechera spp.) (Corral 
et al., 2013), HAPPY, HPARI (ARIADNE7; H. perforatum) (Schallau et al., 2010), those controlling parthenogenesis, such as ASGR-BBML (Apospory Specific Genomic Region-Baby Boom; Pennisetum squamulatum) (Conner et al., 2015); as well as that modulating endosperm development, such as PsORC3a (Origin Recognition Complex; P. simplex) (Siena et al., 2016) and AutE (AED; Hieracium subgenus Pilosella species) (Henderson et al., 2017). Promising results towards introduction of the parthenogenesis component of apomixis has been provided by utilizing PSASGR-BBML gene, which successfully developed parthenogenetic haploids in sexual crops such as pearl millet, rice and maize (Conner et al., 2015, 2017), and is reported to be conserved across Paniceae species (Worthington et al., 2016).

\section{Factors Affecting Uncoupling and Expression of Partitioned Apomixis Components}

Partitioning of apomixis components and their expression have been found to be largely influenced by genotypic effects, however, they are also affected by ploidy levels and dosage effects, as well as stress and environmental factors. Modifying elements present in the genetic background have also been presumed to modulate the expressivity of apomixis components (Koltunow et al., 1998; Bicknell et al., 2000; Hand et al., 2015), mostly by epigenetic regulatory networks (Curtis and Grossniklaus, 2008; Galla et al., 2017; Bocchini et al., 2018).

In apomictic plants, genotypic effects were identified to be more profound than ploidy effects in determining the mode of reproduction, as well as penetrance and expressivity of the component traits. Although modification of ploidy levels effect partitioning, it is largely found to be genotype-dependent (Burson et al., 2002; Matzk et al., 2005; Kaushal et al., 2008, 2018; Krahulcova and Rotreklova, 2010; Sharbel et al., 2010; Krahulec et al., 2011; Voigt-Zielinski et al., 2012; Delgado et al., 2014; Noyes and Wagner, 2014). Higher ploidy may accumulate the relative doses of the apomeiotic- or sexual-factors, which in turn affects the eventual expression of the trait, especially in facultative genotypes. Such dosage effects on expression of apomeiosis have been reported in apomicts, such as R. auricomus, Erigeron interspecific hybrids, Paspalum rufum, P. maximum, Pennisetum interspecific crosses and Pilosella spp. (Nogler, 1984b; Noyes, 2005; Kaushal et al., 2008, 2010; Krahulcova et al., 2011; Delgado et al., 2016). Interestingly, an enhancement in sexuality (or reduction in apospory) has been reported with rise in ploidy in a P. maximum ploidy series $(2 n=6 x$ to $11 x)$ (Kaushal et al., 2018).

In general, occurrence of the apomeiosis:zygotic-embryogenesis pathway (leading to $\mathrm{B}_{\mathrm{III}}$ hybrids) is reported more frequently than the meiotic:parthenogenesis pathway $\left(\mathrm{M}_{1}\right.$, di/poly-haploids) (Bicknell et al., 2003; Aliyu et al., 2010; Hojsgaard et al., 2014a; Schinkel et al., 2017; Klatt et al., 2018a). However, $\mathrm{B}_{\mathrm{III}}$ formation is found largely to be genotype-dependent and ploidy level has little effect on the expression of partitioned apomeiosis. In fact, partitioning and formation of $\mathrm{B}_{\mathrm{III}}$ hybrids have been recently reported in diploid individuals in agamic complexes of Boechera and Ranunculus (Aliyu et al., 2010; Hojsgaard et al., 2014a; Schinkel et al., 2017; Klatt et al., 2018b;
Barke et al., 2018). On the other hand, expression of the parthenogenesis component is highly influenced by the ploidy variations exhibiting high positive correlation with increasing ploidy (Kaushal et al., 2009; Aliyu et al., 2010; Noyes and Wagner, 2014). Recently, a strong relationship was identified between rise in ploidy and frequency of haploid production in plants with $6 x$ ploidy and more $(2 n=6 x$ till $2 n=11 x)$ in an exhaustive ploidy series of $P$. maximum (Kaushal et al., 2018), suggesting that these "parthenogenetic factors" may also act in a dosage dependent manner. Different effects of changes in ploidy level on expression of apomeiosis and parthenogenesis suggest existence of different mechanisms controlling these two traits (reviewed in Sokolov et al., 2008). Haploids (or polyhaploids), resultant of haploid parthenogenesis are rare in diploid plants, explainable on the basis of minimum gene-dosage model, segregation-distortion model, or gametophyte-expressed lethal model (reviewed in Bicknell and Koltunow, 2004; Talent, 2009; Cosendai and Horandl, 2010). From an evolutionary perspective, these partitioned components act as a natural phenomenon to enrich the species diversity and speciation through polyploidpolyhaploid-polyploid cycles, as demonstrated in D. annulatum (de Wet, 1968), P. maximum (Savidan and Pernes, 1982), Eragrostis curvula (Mecchia et al., 2007), Boechera spp. (Aliyu et al., 2010) and Erigeron spp. (Noyes and Wagner, 2014).

In addition to the above factors (genotype and ploidy), environmental stresses, such as higher elevations, extreme temperatures and edaphic factors, seasonal variations, nutrition, herbivory and diseases, as well as pollination timings, are also known to affect the expressivity and penetrance of apomeioisis and parthenogenesis traits (Cosendai and Horandl, 2010; Mason and Pires, 2015; Schinkel et al., 2016; Shah et al., 2016; Kreiner et al., 2017; Rodrigo et al., 2017; Kirchheimer et al., 2018; Klatt et al., 2018b). A role of stress hormone signaling has been proposed for initiating such responses and has been studied in biochemical as well as evolutionary perspectives (Koltunow et al., 2001; Polegri et al., 2010; Horandl and Hadacek, 2013). In-fact it would be interesting to identify a stress-activated molecular switch that can trigger the expression of apomixis components or vice versa. Timing of pollination is also reported to be a factor affecting frequency of $\mathrm{B}_{\mathrm{III}}$ hybridization events (Martinez et al., 1994; Burson et al., 2002; Espinoza et al., 2002).

Recombination between components may also modify mode of endosperm development in a genotype dependent manner. Such modifications are largely identified to be genotypedependent, with little effect of the ploidy levels, and modulated by still unknown regulatory factors ( $\mathrm{Li}$ et al., 2014; Hand et al., 2015; Gehring and Satyaki, 2017; Henderson et al., 2017; Kaushal et al., 2018).

\section{PANICUM MAXIMUM AS A MODEL SYSTEM TO STUDY PARTITIONING OF APOMIXIS COMPONENTS}

Panicum maximum Jacq. (syn. Megathyrsus maximus, family: Poaceae, subfamily: Panicoideae, tribe: Paniceae), commonly known as guinea grass, is a suitable system for polyploidy 
and apomixis research. It is a tall, high yielding, nutritious, perennial, high seed setter, and multi-cut forage grass, adapted to humid, semi-arid and arid environments. This crop possesses substantial variability in morphology, breeding and agronomic traits (Malaviya, 1998; Kaushal et al., 1999; Sukhchain, 2010), and the global germplasm diversity has been characterized for cytological, biochemical and molecular features (Jain et al., 2003, 2006; Ebina et al., 2007; Chandra and Tiwari, 2010; Sousa et al., 2011).

Naturally occurring forms are predominated by apomictic tetraploid cytotypes $(2 n=4 x=32)$, with occasional reports of sexual diploids $(2 n=16)$ and facultative hexaploids $(2 n=48)$ (Savidan, 2000; Jain et al., 2003; Kaushal et al., 2008). Sexually reproducing tetraploid lines are also reported to occur naturally as well as in experimentally induced polyploids (Nakajima et al., 1979; Hanna and Nakagawa, 1994). It has a smaller genome size (ca. $500 \mathrm{Mbp}$ ) and ca. $0.9 \mathrm{pg}$ sporophytic DNA content (in diploid strains) (Akiyama et al., 2008; Kaushal et al., 2009). Availability of sexual as well as apomictic forms within the same ploidy level makes it a suitable system to generate desired populations to undertake inheritance and molecular biology studies.

The mode of seed formation is apospory:parthenogenesis:pseudogamous-endosperm in apomictic forms, while sexual genotypes produce seeds by syngamy of reduced male and female gametes, followed by pseudogamous endosperm development. Apomeiosis is characterized by Panicum-type aposporous ES (2 synergids, 1 egg cell, 1 polar nucleus; all 4-nuclei are unreduced), while sexual lines exhibit typical Polygonum-type reduced ES (2 synergids, 1 egg cell, 2 polar nuclei, 3 antipodals; all eight nuclei are reduced). Anatomical differences between aposporous and sexual ES permit rapid analysis for identification of mode of reproduction in germplasm and segregating populations (Nakagawa, 1990).

A dominant single gene model for controlling apomixis in guinea grass has been widely accepted (Savidan, 1980, 2000; Ebina et al., 2005), governing apomixis phenotype in simplex condition (Aaaa). Development of aposporous ES has been extensively studied cytologically and ultra-structurally (reviewed in Chen and Guan, 2012). Although still to be genomesequenced, this crop is rich in available genomic resources. Molecular markers (RAPD, RFLP, AFLP, SSR and ESTs) linked to apomixis have been developed and the aposporous linkage group has been constructed (Ebina et al., 2005; Bluma-Marques et al., 2014). Expressed sequence tags (ESTs) led to identification of aposporous ovary-specific genes (Yamada-Akiyama et al., 2009). Richness of molecular resources in this crop is further strengthened by availability of extensive genomic databases in its close relative Panicum virgatum (switch grass) (Sharma et al., 2012; Zhang et al., 2013).

An Apomixis Specific Gene (ASG-1), that showed stage specific expression in developing buds of apomictic types only, has been identified and characterized through comparative gene expression analysis (Chen et al., 1999, 2005). Transcriptome data has been generated comparing the gametogenesis stages between apomictic and sexual forms (Radhakrishna et al., 2018). Recently, irradiation-induced deletion mutants for the apomixis, controlling genomic region in tetraploid guinea grass, showed loss-of-apomixis phenotype and replaced aposporous (Panicum-type) ES with sexual type (Polygonum-type) (Takahara et al., 2016).

In contrast to a general understanding of apomixis under monogenic control, a wide scale screening of guinea grass germplasm suggested multigene control of the trait. Uncoupling of the apomixis components was demonstrated in more than $67 \%$ of the global germplasm accessions, suggesting frequent occurrence of recombination between apomeiosis and parthenogenesis components (Kaushal et al., 2009). Germplasm lines with high $\mathrm{B}_{\mathrm{III}}$ and $\mathrm{M}_{1}$ formation were also identified. Reproductive diversity for seed formation estimated through reconstruction of reproductive pathways (utilizing ES and FCSS analysis), in tetraploid and hexaploid guinea grass lines, suggested that the three components (apomeiosis, parthenogenesis and functional endosperm development) recombined freely and all phenotypic classes expected from such recombination events were recovered (Figure 1 and Table 1) (Kaushal et al., 2008). Identification of certain modified pathways e.g., presence of two polar nuclei in aposporous ES fusing prior to fertilization, and fusion of only one polar nucleus in a sexual ES, provides the opportunity for better insights into seed development processes. The flexibility of guinea grass to demonstrate aposporous and sexual ES, parthenogenetic and zygotic embryo development, and pseudogamous and AED (in ovules and matured seeds) offer advantages to understand the interaction effects arising due to recombination between these apomixis components.

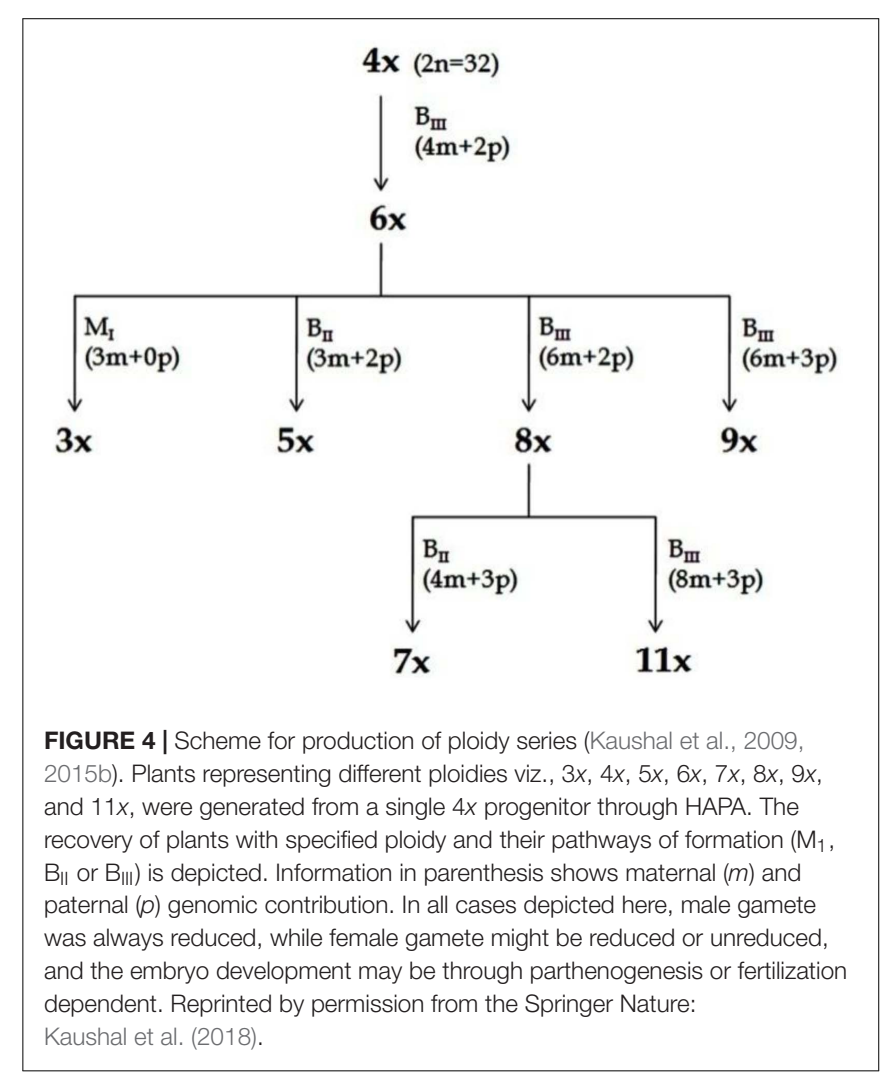



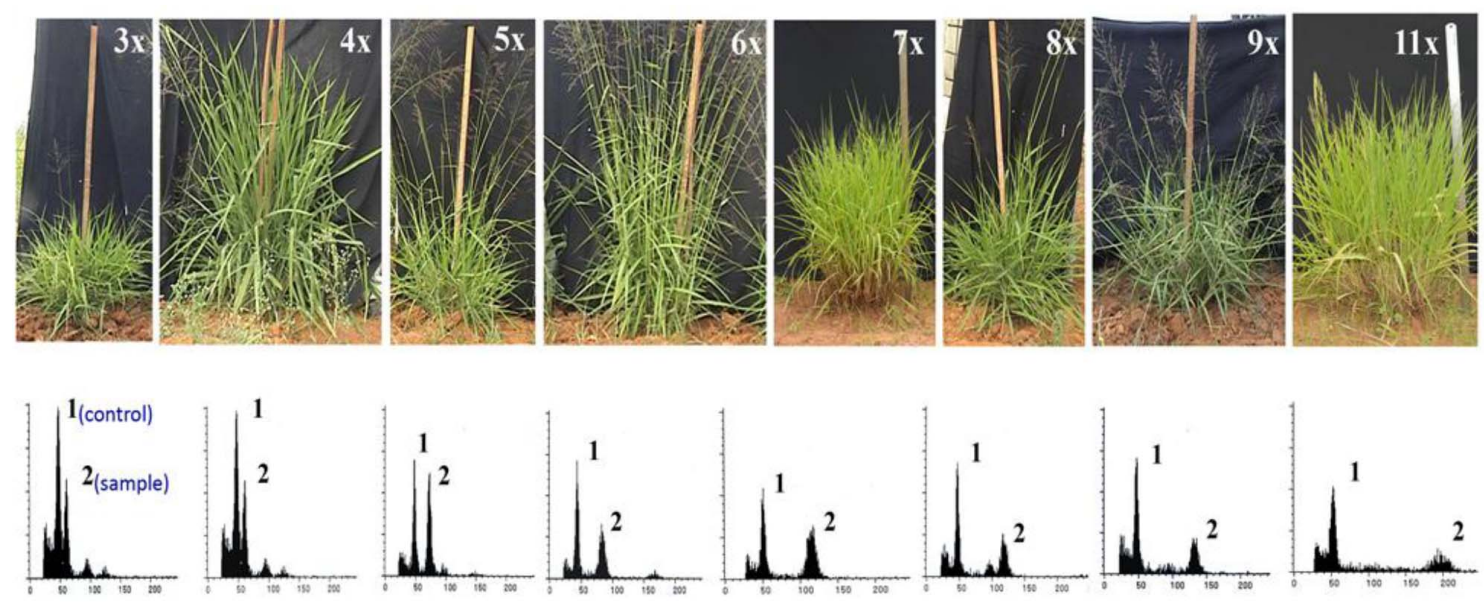

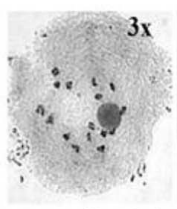

$(2 n=24)$

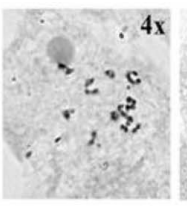

32

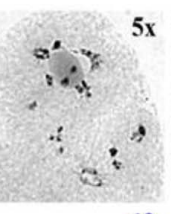

40

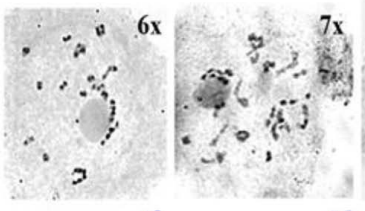

48

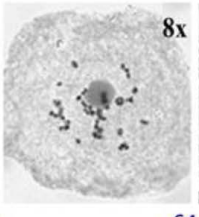

56

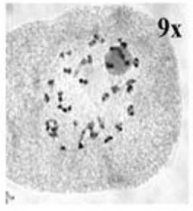

64

72

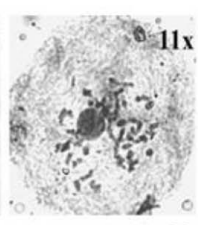

88

FIGURE 5 | Morphological, flow cytometric and meiotic chromosomes characterization of a ploidy series in guinea grass, represented by $3 x, 4 x, 5 x, 6 x, 7 x, 8 x, 9 x$, and $11 x$ cytotypes, generated through HAPA. Upper lane: morphological features of plants representing different ploidies. Vertical scale represents $100 \mathrm{~cm}$ height; Middle lane: Flow cytometric histograms from plant sample alongwith internal control, obtained from leaf tissues of plants representing various ploidies represented in upper lane, respectively. A triploid (3x) plant was used as the internal control, represented by peak 1 in all FCM histograms; peak 2 was of the sample. Smaller peaks arise from G2 phase cells. Leaves of $4 x$ plant were used as the internal control for $3 x$, and hence the histograms of $3 x$ and $4 x$ plants were same; Lower lane: meiotic chromosome configurations of plants representing ploidies $3 x$ till $9 x$ and $11 x$. Adapted and modified with permission from Kaushal et al. (2009). Reprinted by permission from John Wiley and Sons: Kaushal et al. (2009).

Consequences of partitioned apomixis components, leading to the formation of triploids ( $3 n, \mathrm{~B}_{\mathrm{III}}$ hybridization) and/ or haploids ( $1 n, \mathrm{M}_{1}$ progeny), was utilized to develop a Hybridization-supplemented Apomixis-components Partitioning Approach (HAPA) for ploidy manipulations without using any chemical agent or in vitro processing. Utilizing HAPA, an exhaustive ploidy series has been developed from a single $4 x(2 n=32)$ progenitor, represented by $3 x, 4 x, 5 x$, $6 x, 7 x, 8 x, 9 x$, and $11 x$ cytotypes (Kaushal et al., 2009, 2015b) (Figures 4, 5). Such an exhaustive ploidy series offers an excellent system to understand ploidy regulated trait expression with respect to apomixis and its component traits. Male fertility is maintained at all these ploidy levels, providing a better scope for genetical and breeding experiments (Kaushal et al., 2018). Guinea grass is, thus, found to possess extraordinary flexibility to accommodate extreme genome dosage $(2 n=2 x$ till $11 x)$, chromosome numbers $(2 n=2 x=16$ till $2 n=11 x=88)$ and sporophytic DNA content (1.8 pg to $5.0 \mathrm{pg}$ ), and is still capable of producing functional female gametes (both reduced and unreduced) and male (mostly reduced) gametes.

Ploidy effects on overall expression on apomixis revealed that the eventual phenotype depends on relative doses of apospory and parthenogenesis factors (Kaushal et al., 2018). Intriguingly, the proportion of facultatively reproducing progenies increased with the enhancement in ploidy levels. The phenotypic expression of partitioned apomictic components demonstrated $\mathrm{B}_{\mathrm{III}}$ hybridization and AED to be less effected by the change in ploidy and were mostly dependent on genotypic effects. However, formation of $M_{1}$ progeny was highly affected by a rise in ploidy, however, appeared only in plants with $6 x$ ploidy or more (Combes, 1975; Kaushal et al., 2008, 2018). Availability of genotypes with similar ploidy level but contrasting capacities for partitioned components (extreme high or low frequency of formation of $\mathrm{B}_{\mathrm{III}}$ or $\mathrm{M}_{1}$ progeny) are important resources to identify differentially expressed genes governing these partitioned components.

Endosperm development in guinea grass is intriguing, considering the fact that the typical 2:3 genome ratios is conserved in the embryo and endosperm of matured seeds by virtue of modification in the embryo-sac, which is a 4nucleated Panicum type (as discussed earlier). However, it shows extraordinary flexibility in tolerating excessive deviance from typical 2em:3end genome ratios, as well as maternal and paternal genome contributions in developing embryos and endosperms. Em:End genome ratios tolerated are 2:3 (in $\mathrm{B}_{\mathrm{II}} / \mathrm{M}_{\mathrm{II}}$ progenies), 1:1 (in $\mathrm{B}_{\text {III }}$ ) and 1:3 (in $\mathrm{M}_{1}$ ) (Table 1). As an illustration, a $11 x(2 n=88)$ plant will have $11 \mathrm{em}: 16.5 \mathrm{end}$ and $\approx 16.5 \mathrm{em}: 16.5 \mathrm{end}$ genome ratio in typical apomictic and $\mathrm{B}_{\mathrm{III}}$ seed, respectively. Successful recovery of seeds, representing almost all categories $\left(\mathrm{B}_{\mathrm{II}} / \mathrm{M}_{\mathrm{II}}, \mathrm{B}_{\mathrm{III}}\right.$ and $\left.\mathrm{M}_{1}\right)$ from plants 
representing ploidy series (see Table 1), suggests that EBN and endosperm imprinting constraints are largely relaxed in this crop (Kaushal et al., 2018). Recovery of fertile seeds from such diverse categories is also important for studying nucleo-cytoplasm as well as embryo-endosperm interactions and the ovule molecular-machinery capable of bearing such high genomic content.

The diversity in pathways of seed formation, availability of plants representing different modes of reproduction and different ploidy levels, male fertility in plants with higher ploidies and successful recovery of seeds at extremely higher ploidies (some of them expressing $\mathrm{B}_{\mathrm{III}}$ and $\mathrm{M}_{1}$ hybridization), all make this crop a potentially useful system for undertaking investigations in apomixis genetics and breeding, as well as cytogenetical and molecular studies on partitioned apomixis components.

\section{UTILIZATION OF PARTITIONED APOMIXIS COMPONENTS}

Understanding the partitioning phenomenon as well as utilization of the partitioned apomixis components have experimental and applied consequences. The foremost importance is towards a better understanding of apomeiotic ES development as well as elucidating parthenogenetic factors responsible for autonomous egg cell development, as the plant material polymorphic for differential capacities for these components is now available (Koltunow et al., 2011; Sahu et al., 2012; Hojsgaard et al., 2014a). It also may shed light on embryo-endosperm interactions especially for EBN and endosperm imprinting effects, chromatin dynamics, evolution of components, and more specifically the progression of the components in apomixis process.

Partitioning apomeiosis from parthenogenesis also allows for generation of variability, because the two stages of variability generation, viz., meiosis and fertilization, respectively, are rendered operational. Such possibilities eventually defy the perception considering apomixis as evolutionary dead-end and road-block to plant breeding (Darlington, 1939; Grant, 1981). Variability has been successfully generated through addition of genomes utilizing $\mathrm{B}_{\mathrm{III}}$ hybridization in otherwise apomictic species, such as Brachiaria decumbens, Panicum maximum, Poa pratensis, E. curvula, C. ciliaris, Pennisetum orientale etc. (Bashaw and Hignight, 1990; Nogler, 1994; Naumova et al., 1999; Matzk et al., 2005; Kaushal et al., 2015a, 2018). In fact, $B_{\text {III }}$ hybrids are formed directly, without intermediary of sexual relatives, and thus give rise to new apomictic biotypes, thereby further increasing the polymorphism of the agamic species complex (Nogler, 1994). Additionally, polyhaploids generated through the $\mathrm{M}_{1}$ pathway offer added advantage for understanding apomixis expression at diploid/haploid levels. Polyploid-polyhaploid cycles for generation and fixation of variability in natural polyploids have already been discussed (reviewed in Berthaud, 2001). Although rarely reported, partitioning also presents a possibility of obtaining sexual polyhaploids from apomictic polyploids where apomixis is under monogenic control, such as $P$. maximum (Aaaa). Such sexual polyhaploids would be a resource for breeding apomictic crops where naturally occurring apomicts are polyploids.

Recombination between apomixis components presents a system to study diversity in reproductive pathways of seed development. Such systems, when duly coupled with polyploidy, offer advantages for precise understanding of the various mechanisms, leading to interaction effects between apomixis components as well as their interface with genetic, epigenetic and environmental factors (Matzk et al., 2001, 2005; Aliyu et al., 2010; Hojsgaard, 2018). Additionally, it also serves as a stable system to generate newer cytotypes, through $\mathrm{B}_{\mathrm{III}}, \mathrm{M}_{1}$ or HAPA (Kaushal et al., 2009, 2015a).

Although there are several reports whereby mutagenesis in natural apomictic plants converted them to sexual (Takahara et al., 2014, 2016), reports of a single mutation converting a sexual plant to apomictic are extremely rare (Chen et al., 2018; Gaafer et al., 2018). The strategy and application rely on generating (or inducing) individual components (say apomeiosis and parthenogenesis) separately and then attempting to reconstruct the apomixis phenotype by combining these components into one background. Organizing partitioned apomixis elements to develop an apomictic crop is a major challenge for plant breeders. In-fact, the most plausible approach to engineer apomixis into present day crop plants would be an applied synergy between "evaluation" and "synthesis" approaches. Evaluation precisely generates information from natural apomicts for identification of genes (apomixis per se or its components), gene actions and other required factors (e.g., environment, ploidy etc.), which may be appropriately utilized in "synthesis" approach to transfer/induce into sexually reproducing crops of interest, or to engineer key genes governing sexuality (Bicknell and Koltunow, 2004; Kaushal et al., 2004, 2005; Barcaccia and Albertini, 2013; Hand and Koltunow, 2014; Mieulet et al., 2016; Khanday et al., 2019). Identification of key masterregulatory sequences has been long sought, which may govern entry into apomeiotic/meiotic ES development as well as parthenogenetic/zygotic development of egg cell, however, the underlying mechanism is still poorly understood. Accordingly, based on recent discoveries of key genes, a strategy to introduce a transgene "apomixis cassette" containing dominant genes conferring to apomeiosis, parthenogenesis and autonomous development, has been proposed to generate an apomictic crop (Conner and Ozias-Akins, 2017). Two alternative pathways have been suggested: utilizing an artificial miRNA (amiRNA) $\mathrm{MiMe}$ cassette and an egg-specific promoter fused with a weak $\mathrm{CENH3}$ variant cassette to generate a $\mathrm{MiMe}+\mathrm{GEM}$ apomictic transgene line, or using amiRNA MiMe cassette to create a MiMe + PsASGR-BBML apomictic transgene line. MiMe lines may generate unreduced egg cells by replacing meiosis with mitosis (d'Erfurth et al., 2009), while CENH3/GEM (Ravi and Chan, 2010; Marimuthu et al., 2011) and PsASGR-BBML (Conner et al., 2015) may induce parthenogenesis. The endosperm in these cases will maintain the required $2 m: 1 p$ ratio. Partial apomixis in rice has been recently achieved by triggering parthenogenesis in MiMe generated unreduced female gametes by ectopic expression of a male specific OsBBM gene in unfertilized ovules (Khanday et al., 2019). Another plausible approach to develop 
an apomictic cereal could be to introduce/reassemble apomeiosis and parthenogenesis, along with AED, however, to avoid gene flow, the final genotype must be male sterile (Kaushal et al., 2004).

\section{CONCLUSION}

Apomictic mode of reproduction is seemingly a complex phenomenon, whereby the eventual expression depends on numerous major and minor factors, in addition to genotypic effects. Availability of recombination potential between its three components (apomeiosis, parthenogenesis and functional endosperm-development) offers advantages for understanding the origin, evolution, genetics and molecular biology of the phenomenon. With the increasing state of knowledge and efficient technological back-up, the biology of these components, independent as well as when linked, has been subjected to intense investigations. Large scale characterization of the reproductive diversity in agamic complexes is expected to unravel detailed insights into the possibility of partitioning. Amongst the components, apomeiosis has been investigated in detail, however, information on parthenogenesis and endosperm development is still inadequate. This is also important in a view to developing a universal model for generating apomictic crops. Comparison of molecular mechanisms governing apomeiosis, parthenogenesis and relaxed endosperm imprinting in apomicts, as compared to development of unreduced egg cell, haploid embryos and endosperm development in sexual crops through alternate

\section{REFERENCES}

Akiyama, Y., Hanna, W. W., and Ozias-Akins, P. (2005). High-resolution physical mapping reveals that the apospory-specific genomic region (ASGR) in Cenchrus ciliaris is located on a heterochromatic and hemizygous region of a single chromosome. Theor. Appl. Genet. 111, 1042-1051. doi: 10.1007/s00122-0050020-5

Akiyama, Y., Yamada-Akiyama, H., Yamanouchi, H., Takahara, M., Ebina, M., Takamizo, T., et al. (2008). Estimation of genome size and physical mapping of ribosomal DNA in diploid and tetraploid guinea grass (Panicum maximum Jacq.). Grassl. Sci. 54, 89-97. doi: 10.1111/j.1744-697X.2008.00110.x

Albertini, E., Marconi, G., Reale, L., Barcaccia, G., Porceddu, A., Ferranti, F., et al. (2005). SERK and APOSTART. candidate genes for apomixis in Poa pratensis. Plant Physiol. 138, 2185-2199. doi: 10.1104/pp.105.062059

Albertini, E., Porceddu, A., Ferranti, F., Reale, L., Barcaccia, G., Romano, B., et al. (2001). Apospory and parthenogenesis may be uncoupled in Poa pratensis, a cytological investigation. Sex. Plant Reprod. 14, 213-217. doi: 10.1007/s00497001-0116-2

Aliyu, O. M., Schranz, M. E., and Sharbel, T. F. (2010). Quantitative variation for apomictic reproduction in the genus Boechera (Brassicaceae). Am. J. Bot. 97, 1719-1731. doi: 10.3732/ajb.1000188

Asker, S. (1967). Induced sexuality after chromosome doubling in an apomictic Potentilla argentea biotype. Hereditas 57, 339-342. doi: 10.1111/j.1601-5223. 1967.tb02116.x

Asker, S. (1980). Gametophytic apomixis: elements and genetic regulation. Hereditas 93, 277-293. doi: 10.1111/j.1601-5223.1980.tb01367.x

Asker, S. E., and Jerling, L. (1992). Apomixis in Plants. Boca Raton, FL: CRC Press.

Barcaccia, G., and Albertini, E. (2013). Apomixis in plant reproduction: a novel perspective on an old dilemma. Plant Reprod. 26, 159-179. doi: 10.1007/s00497013-0222-y

Barcaccia, G., Arzenton, F., Sharbel, T. F., Varotto, S., Parrini, P., and Lucchin, M. (2006). Genetic diversity and reproductive biology in ecotypes of the facultative pathways (e.g., restitution nuclei, endomitosis, uniparental chromosome-elimination, alloplasmic systems), is expected to yield important insights into possible overlaps during the seed formation process. Identification of the master regulatory switch triggering apomixis in sexual crops and sexuality in apomictic crops is a plant breeders' dream. Though amalgamation of information gathered from apomictic and sexual systems (evaluation and synthesis approach) has led to the proposed model towards developing apomictic crops (Pupilli and Barcaccia, 2012; Conner and Ozias-Akins, 2017; Khanday et al., 2019), signaling pathways, cell-to-cell interactions (Juranic et al., 2018), and protein and metabolome investigations may greatly strengthen the state of knowledge.

\section{AUTHOR CONTRIBUTIONS}

PK involved in conceptualization, literature collection, compilation and writing the manuscript. KD, AR, MS, and VK performed literature collection and wrote the manuscript. AR and DM performed compilation and wrote the manuscript.

\section{FUNDING}

This work was supported by Indian Council of Agricultural Research, India, Department of Science and Technology, India, and Department of Biotechnology, India for Apomixis Research.

apomict Hypericum perforatum L. Heredity 96, 322-334. doi: 10.1038/sj.hdy. 6800808

Barcaccia, G., Baumlein, H., and Sharbel, T. (2007). Apomixis in St. John's wort (Hypericum perforatum L.): an overview and glimpse towards the future. Regnum Veg. 147, 259-280.

Barke, H. B., Daubert, M., and Horandl, E. (2018). Establishment of apomixis in diploid F2 hybrids and inheritance of apospory from F1 to F2 hybrids of the Ranunculus auricomus complex. Front. Plant Sci. 9:1111. doi: 10.3389/fpls.2018. 01111

Bashaw, E. C., and Hignight, K. W. (1990). Gene transfer in apomictic buffelgrass through fertilization of an unreduced egg. Crop Sci. 30, 571-575. doi: 10.2135/ cropsci1990.0011183X003000030021x

Berthaud, J. (2001). "Apomixis and the management of genetic diversity," in The Flowering of Apomixis: From Mechanisms to Genetic Engineering, eds Y. Savidan, J. G. Carman, and T. Dresselhaus (Mexico, DF: CIMMYT), 8-23.

Bicknell, R. A., Borst, N. K., and Koltunow, A. M. (2000). Monogenic inheritance of apomixis in two Hieracium species with distinct developmental mechanisms. Heredity 84, 228-237. doi: 10.1046/j.1365-2540.2000.00663.x

Bicknell, R. A., and Koltunow, A. (2004). Understanding apomixis, recent advances and remaining conundrums. Plant Cell 16, S228-S245. doi: 10.1105/tpc.017921

Bicknell, R. A., Lamb, S. C., and Butler, R. C. (2003). Quantification of progeny classes in two facultatively apomictic accessions of Hieracium. Hereditas 138, 11-20. doi: 10.1034/j.1601-5223.2003.01624.x

Bluma-Marques, A. C., Chiari, L., Agnes, D. C., Jank, L., and Pagliarini, M. S. (2014). Molecular markers linked to apomixis in Panicum maximum. Afr. J. Biotechnol. 13, 2198-2202. doi: 10.5897/AJB2014.13703

Bocchini, M., Galla, G., Pupilli, F., Bellucci, M., Barcaccia, G., Ortiz, J. P. A., et al. (2018). The vesicle trafficking regulator PN_SCD1 is demethylated and overexpressed in florets of apomictic Paspalum notatum genotypes. Sci. Rep. 8:3030. doi: 10.1038/s41598-018-21220-4

Brauning, S., Catanach, A., Lord, J. M., Bicknell, R., and Macknight, R. C. (2018). Comparative transcriptome analysis of the wild-type model apomict Hieracium 
praealtum and its loss of parthenogenesis (lop) mutant. BMC Plant Biol. 18:206. doi: 10.1186/s12870-018-1423-1

Brukhin, V. (2017). Molecular and genetic regulation of apomixis. Russ. J. Genet. 53, 943-964. doi: 10.1134/S1022795417090046

Burson, B. L., Hussey, M. A., Actkinson, J. M., and Shafer, G. S. (2002). Effect of pollination time on the frequency of $2 \mathrm{n}+\mathrm{n}$ fertilization in apomictic buffelgrass. Crop Sci. 42, 1075-1080. doi: 10.2135/cropsci2002.1075

Caceres, M. E., Matzk, F., Busti, A., Pupilli, F., and Arcioni, S. (2001). Apomixis and sexuality in Paspalum simplex: characterization of the mode of reproduction in segregating progenies by different methods. Sex. Plant Reprod. 14, 201-206. doi: 10.1007/s00497-001-0109-1

Calderini, O., Chang, S. B., de Jong, H., Busti, A., Paolocci, F., Arcioni, S., et al. (2006). Molecular cytogenetics and DNA sequence analysis of an apomixislinked BAC in Paspalum simplex reveal a non-pericentromere location and partial micro-colinearity with rice. Theor. Appl. Genet. 112, 1179-1191. doi: 10.1007/s00122-006-0220-7

Calzada, J.-P. V., Crane, C. F., and Stelly, D. M. (1996). Apomixis: the asexual revolution. Science 274, 1322-1323. doi: 10.1126/science.274.5291.1322

Carman, J. G. (1997). Asynchronous expression of duplicate genes in angiosperms may cause apomixis, bispory, tetraspory, and polyembryony. Biol. J. Linn. Soc. 61, 51-94. doi: 10.1111/j.1095-8312.1997.tb01778.x

Catanach, A. S., Erasmuson, S. K., Podivinsky, E., Jordan, B. R., and Bicknell, R. A. (2006). Deletion mapping of genetic regions associated with apomixis in Hieracium. Proc. Natl. Acad. Sci. U.S.A. 103, 18650-18655. doi: 10.1073/pnas. 0605588103

Chandra, A., and Tiwari, K. K. (2010). Isolation and characterization of microsatellite markers from guinea agrass (Panicum maximum) for genetic diversity estimate and cross-species amplification. Plant Breed. 129, 120-124. doi: 10.1111/j.1439-0523.2009.01651.x

Chen, L., and Guan, L. (2012). "Ultrastructural mechanisms of aposporous embryo sac initial cell appearance and its developmental process in gametophytic apomicts of Guinea grass (Panicum maximum)," in The Transmission Electron Microscope, ed. K. Maaz (Rijeka: InTech). doi: 10.5772/34912

Chen, L., Guan, L., Sio, M., Hoffmann, F., and Adachi, T. (2005). Developmental expression of ASG-1 during gametogenesis in apomictic guinea grass (Panicum maximum). J. Plant Physiol. 162, 1141-1148. doi: 10.1016/j.jplph.2005.02.010

Chen, L., Miyazaki, C., Kojima, A., Saito, A., and Adachi, T. (1999). Isolation and characterization of a gene expressed during early embryo sac development in apomictic Guinea grass (Panicum maximum). J. Plant Physiol. 154, 55-62. doi: 10.1016/S0176-1617(99)80318-6

Chen, X., Lai, H. G., Sun, Q., Liu, J. P., Chen, S. B., and Zhu, W. L. (2018). Induction of apomixis by dimethyl sulfoxide (DMSO) and genetic identification of apomictic plants in cassava. Breed. Sci. 68, 227-232. doi: 10.1270/jsbbs.17089

Combes, D. (1975). Polymorphisme et mode de reproduction dans la section des Maximae du genre Panicum (Graminees) en Afrique. Coll. Menoires ORSTOM $77,1-100$.

Conner, J. A., Goel, S., Gunawan, G., Cordonnier-Pratt, M. M., Johnson, V. E., Liang, C., et al. (2008). Sequence analysis of bacterial artificial chromosome clones from the apospory-specific genomic region of Pennisetum and Cenchrus. Plant Physiol. 147, 1396-1411. doi: 10.1104/pp.108.119081

Conner, J. A., Gunawan, G., and Ozias-Akins, P. (2013). Recombination within the apospory specific genomic region leads to the uncoupling of apomixis components in Cenchrus ciliaris. Planta 238, 51-63. doi: 10.1007/s00425-0131873-5

Conner, J. A., Mookkan, M., Huo, H., Chae, K., and Ozias-Akins, P. (2015). A parthenogenesis gene of apomictic origin elicits embryo formation from unfertilized eggs in a sexual plant. Proc. Natl. Acad. Sci. U.S.A. 112, 1120511210. doi: $10.1073 /$ pnas. 1505856112

Conner, J. A., and Ozias-Akins, P. (2017). Apomixis: engineering the ability to harness hybrid vigor in crop plants. Methods Mol. Biol. 1669, 17-34. doi: 10. 1007/978-1-4939-7286-9_2

Conner, J. A., Podio, M., and Ozias-Akins, P. (2017). Haploid embryo production in rice and maize induced by PsASGR-BBML transgenes. Plant Reprod. 30, 41-52. doi: 10.1007/s00497-017-0298-x

Corral, J. M., Vogel, H., Aliyu, O. M., Hensel, G., Thiel, T., Kumlehn, J., et al. (2013). A conserved apomixis-specific polymorphism is correlated with exclusive exonuclease expression in premeiotic ovules of apomictic Boechera species. Plant Physiol. 163, 1660-1672. doi: 10.1104/pp.113.222430
Cosendai, A.-C., and Horandl, E. (2010). Cytotype stability, facultative apomixis and geographical parthenogenesis in Ranunculus kuepferi (Ranunculaceae). Ann. Bot. 105, 457-470. doi: 10.1093/aob/mcp304

Crane, C. F. (2001). "Classification of apomixis mechanisms," in The Flowering of Apomixis: From Mechanisms to Genetic Engineering, eds Y. Savidan, T. Dresselhaus, and J. G. Carman (Mexico, DF: CIMMYT).

Curtis, M. D., and Grossniklaus, U. (2008). Molecular control of autonomous embryo and endosperm development. Sex. Plant Reprod. 21, 79-88. doi: 10.1007/s00497-007-0061-9

Darlington, C. D. (1939). The Evolution of Genetic Systems. Cambridge: Cambridge University Press.

de Wet, J. M. J. (1968). Diploid-tetraploid-haploid cycles and the origin of variability in Dichanthium agamo species. Evolution 22, 394-397. doi: 10.1111/ j.1558-5646.1968.tb05906.x

Delgado, L., Galdeano, F., Sartor, M. E., Quarin, C. L., Espinoza, F., and Ortiz, J. P. A. (2014). Analysis of variation for apomictic reproduction in diploid Paspalum rufum. Ann. Bot. 113, 1211-1218. doi: 10.1093/aob/mcu056

Delgado, L., Sartor, M. E., Espinosa, F., Soliman, M., Galdeano, F., and Ortiz, J. P. A. (2016). Hybridity and auto polyploidy increase the expressivity of apospory in diploid Paspalum rufum. Plant Syst. Evol. 302, 1471-1481. doi: 10.1007/s00606016-1345-z

Depetris, M. B., Acuna, C. A., Pozzi, F. I., Quarin, C. L., and Felitti, S. A. (2018). Identification of genes related to endosperm balance number insensitivity in Paspalum notatum. Crop Sci. 58, 813-822. doi: 10.2135/cropsci2017. 04.0260

d'Erfurth, I., Jolivet, S., Froger, N., Catrice, O., Novatchkova, M., and Mercier, R. (2009). Turning meiosis into mitosis. PLoS Biol. 7:e1000124. doi: 10.1371/ journal.pbio.1000124

Ebina, M., Kouki, K., Tsuruta, S., Akashi, R., Yamamoto, T., Takahara, M., et al. (2007). Genetic relationship estimation in guinea grass (Panicum maximum Jacq.) assessed on the basis of simple sequence repeat markers. Grassl. Sci. 53, 155-164. doi: 10.1111/j.1744-697X.2007.00086.x

Ebina, M., Nakagawa, H., Yamamoto, T., Araya, H., Tsuruta, S., Takahara, M., et al. (2005). Co-segregation of AFLP and RAPD markers to apospory in guinea grass (Panicum maximum Jacq.). Grassl. Sci. 51, 71-78. doi: 10.1111/j.1744-697X. 2005.00011.x

Ellerstrom, S., and Zagorcheva, L. (1977). Sterility and apomictic embryo sac formation in Raphanobrassica. Hereditas 87, 107-120. doi: 10.1111/j.1601-5223. 1977.tb01251.x

Espinoza, F., Pessino, S. C., Quarin, C. L., and Valle, E. M. (2002). Effect of pollination timing on the rate of apomictic reproduction revealed by RAPD markers in Paspalum notatum. Ann. Bot. 89, 165-170. doi: 10.1093/aob/mcf024

Forster, B. P., Heberle-Bors, E., Kasha, K. J., and Touraev, A. (2007). The resurgence of haploids in higher plants. Trends Plant Sci. 12, 368-375. doi: 10.1016/j. tplants.2007.06.007

Gaafer, R. M., El Shanshoury, A. R., El Hisseiwy, A. A., AbdAlhak, M. A., Omar, A. F., El Wahab, M. M. A., et al. (2018). Induction of apomixis and fixation of heterosis in Egyptian rice Hybrid1 line using colchicine mutagenesis. Ann. Agric. Sci. 62, 51-60. doi: 10.1016/j.aoas.2017.03.001

Galla, G., Zenoni, S., Avesani, L., Altschmied, L., Rizzo, P., Sharbel, T. F., et al. (2017). Pistil transcriptome analysis to disclose genes and gene products related to aposporous apomixis in Hypericum perforatum. Front. Plant Sci. 8:79. doi: $10.3389 /$ fpls.2017.00079

Gehring, M., and Satyaki, P. R. (2017). Endosperm and imprinting, inextricably linked. Plant Physiol. 173, 143-154. doi: 10.1104/pp.16.01353

Grant, V. (1981). Plant Speciation. New York, NY: Columbia University Press.

Grimanelli, D. (2012). Epigenetic regulation of reproductive development and the emergence of apomixis in angiosperms. Curr. Opin. Plant Biol. 15, 57-62. doi: 10.1016/j.pbi.2011.10.002

Grimanelli, D., Garcia, M., Kaszas, E., Perotti, E., and Leblanc, O. (2003). Heterochronic expression of sexual reproductive programs during apomictic development in Tripsacum. Genetics 165, 1521-1531.

Grimanelli, D., Leblanc, O., Perotti, E., and Grossniklaus, U. (2001). Developmental genetics of gametophytic apomixis. Trends Genet. 17, 597-604. doi: 10.1016/S0168-9525(01)02454-4

Gupta, S., Bhat, B. V., Bhat, V., Gupta, M. G., and Ahmad, S. T. (1999). Estimation of frequency of apomixis by auxin induced parthenocarpy technique in Dichanthium annulatum (Forssk.) Stapf. Range Manag. Agrofor. 19, 53-58. 
Hand, M. L., and Koltunow, A. M. G. (2014). The genetic control of apomixis: asexual seed formation. Genetics 197, 441-450. doi: 10.1534/genetics.114. 163105

Hand, M. L., Vit, P., Krahulcova, A., Johnson, S. D., Oelkers, K., Siddons, H., et al. (2015). Evolution of apomixis loci in Pilosella and Hieracium (Asteraceae) inferred from the conservation of apomixis- linked markers in natural and experimental populations. Heredity 114, 17-26. doi: 10.1038/hdy.2014.61

Hanna, W. W., and Nakagawa, H. (1994). Registration of Tift SPM92 sexual guinea grass germplasm. Crop Sci. 34:547. doi: 10.2135/cropsci1994. 0011183X003400020064x

Henderson, S. T., Johnson, S. D., Eichmann, J., and Koltunow, A. M. G. (2017). Genetic analyses of the inheritance and expressivity of autonomous endosperm formation in Hieracium with different modes of embryo sac and seed formation. Ann. Bot. 119, 1001-1010. doi: 10.1093/aob/mcw262

Hermann, S. R., Aitken, K. S., Jackson, P. A., George, A. W., Piperidis, N., Wei, X., et al. (2012). Evidence for second division restitution as the basis for $2 \mathrm{n}+$ n maternal chromosome transmission in a sugarcane cross. Euphytica 187, 359-368. doi: 10.1007/s10681-012-0698-9

Herr, J. M. Jr. (2000). Clearing techniques for unusual studies in seed plant embryology. Bot. Guidebooks 24, 25-39.

Hojsgaard, D. (2018). Transient activation of apomixis in sexual neotriploids may retain genomically altered states and enhance polyploid establishment. Front. Plant Sci. 9:230. doi: 10.3389/fpls.2018.00230

Hojsgaard, D., Greilhuber, J., Pellino, M., Paun, O., Sharbel, T. F., and Horandl, E. (2014a). Emergence of apospory and bypass of meiosis via apomixis after sexual hybridisation and polyploidisation. New Phytol. 204, 1000-1012. doi: 10.1111/ nph.12954

Hojsgaard, D., Klatt, S., Baier, R., Carman, J. G., and Horandl, E. (2014b). Taxonomy and biogeography of apomixis in angiosperms and associated biodiversity characteristics. Crit. Rev. Plant Sci. 33, 414-427.

Hojsgaard, D. H., Martinez, E. J., and Quarin, C. L. (2012). Competition between meiotic and apomictic pathways during ovule and seed development results in clonality. New Phytol. 197, 336-347. doi: 10.1111/j.1469-8137.2012.04381.x

Horandl, E. (2009). "Geographical parthenogenesis: opportunities for asexuality," in Lost Sex, The Evolutionary Biology of Parthenogenesis, eds I. Schön, K. Martens, and P. van Dijk (Dordrecht: Springer), 161-186.

Horandl, E., and Hadacek, F. (2013). The oxidative damage initiation hypothesis for meiosis. Plant Reprod. 26, 351-367. doi: 10.1007/s00497-013-0234-7

Indian Grassland and Fodder Research Institute [IGFRI] (2013). Indian Grassland and Fodder Research Institute. Annual Report 2012-13. Jhansi: IGFRI, 19.

Ishii, T., Karimi-Ashtiyani, R., and Houben, A. (2016). Haploidization via chromosome elimination: means and mechanisms. Annu. Rev. Plant Biol. 67, 421-438. doi: 10.1146/annurev-arplant-043014-114714

Jain, A., Roy, A. K., Kaushal, P., Malaviya, D. R., and Zadoo, S. N. (2006). Isoenzyme banding pattern and estimation of genetic diversity among guinea grass germplasm. Genet. Resour. Crop Evol. 53, 339-347. doi: 10.1007/s10722004-0574-0

Jain, A., Zadoo, S. N., Roy, A. K., Kaushal, P., and Malaviya, D. R. (2003). Meiotic system and probable basic chromosome number of Panicum maximum Jacq. accessions. Cytologia 68, 7-13. doi: 10.1508/cytologia.68.7

Juranic, M., Tucker, M. R., Schultz, C. J., Shirley, N. J., Taylor, J. M., Spriggs, A., et al. (2018). Asexually female gametogenesis involves contact with a sexually fated megaspore in apomictic Hieracium. Plant Physiol. 177, 1027-1049. doi: $10.1104 /$ pp. 18.00342

Kaushal, P., Agrawal, A., Malaviya, D. R., Siddiqui, S. A., and Roy, A. K. (2009). Ploidy manipulation in guinea grass (Panicum maximum Jacq., Poaceae) utilizing a hybridization-supplemented apomixis-components partitioning approach (HAPA). Plant Breed. 128, 295-303. doi: 10.1111/j.1439-0523.2008. 01567.x

Kaushal, P., Dwivedi, K. K., Radhakrishna, A., Saxena, S., Paul, S., Srivastava, M. K., et al. (2018). Ploidy dependent expression of apomixis and its components in guinea grass (Panicum maximum Jacq.). Euphytica 214, 152-173. doi: 10.1007/ s10681-018-2232-1

Kaushal, P., Khare, A., Siddiqui, S. A., Agrawal, A., Paul, S., Malaviya, D. R., et al. (2010). Morphological, cytological and reproductive characterization of tri-species hybrids (GOS) between Pennisetum glaucum, P. orientale and P. squamulatum. Euphytica 174, 261-281. doi: 10.1007/s10681-010-0152-9
Kaushal, P., Malaviya, D. R., and Roy, A. K. (2004). Prospects for breeding apomictic rice: a reassessment. Curr. Sci. 87, 292-296.

Kaushal, P., Malaviya, D. R., Roy, A. K., Pathak, S., Agrawal, A., Khare, A., et al. (2008). Reproductive pathways of seed development in apomictic guinea grass (Panicum maximum Jacq.) reveal uncoupling of apomixis components. Euphytica 164, 81-92. doi: 10.1007/s10681-008-9650-4

Kaushal, P., Malaviya, D. R., and Singh, K. K. (1999). Evaluation of exotic accessions of guinea grass (Panicum maximum Jacq.). Ind. J. Plant Genet. Resour. 12, 215-218.

Kaushal, P., Dwivedi, K. K., Radhakrishna, A., Srivastava, M. K., Malaviya, D. R., Roy, A. K., et al. (2015a). Development and characterization of a hexaploid Pennisetum orientale $(2 \mathrm{n}=6 \mathrm{x}=54)$ cytotype recovered through BIII hybridization. Cytologia 80, 37-43. doi: 10.1508/cytologia.80.37

Kaushal, P., Paul, S., Saxena, S., Dwivedi, K. K., Chakraborti, M., Radhakrishna, A., et al. (2015b). Generating higher ploidies (7x and 11x) in guinea grass (Panicum maximum Jacq.) utilizing reproductive diversity and uncoupled apomixis components. Curr. Sci. 109, 1392-1395.

Kaushal, P., Zadoo, S. N., Malaviya, D. R., and Roy, A. K. (2005). Apomixis research in India, past efforts and future strategies. Curr. Sci. 89, 1092-1096.

Khanday, I., Skinner, D., Yang, B., Mercier, R., and Sundaresan, V. (2019). A maleexpressed rice embryogenic trigger redirected for asexual propagation through seeds. Nature 565, 91-95. doi: 10.1038/s41586-018-0785-8

Kirchheimer, B., Wessely, J., Gattringer, A., Huelber, K., Moser, D., Schinkel, C. C. F., et al. (2018). Reconstructing geographical parthenogenesis: effect of niche differentiation and reproductive mode on Holocene range expansion of an alpine plant. Ecol. Lett. 21, 392-401. doi: 10.1111/ele.12908

Klatt, S., Hadacek, F., Hodac, L., Brinkmann, G., Eilerts, M., Hojsgaard, D., et al. (2018a). Photoperiod extension enhances sexual megaspore formation and triggers metabolic reprogramming in facultative apomictic Ranunculus auricomus. Front. Plant Sci. 7:278. doi: 10.3389/fpls.2016.00278

Klatt, S., Schinkel, C. C. F., Kirchheimer, B., Dullinger, S., and Horandl, E. (2018b). Effects of cold treatments on fitness and mode of reproduction in the diploid and polyploid alpine plant Ranunculus kuepferi (Ranunculaceae). Ann. Bot. 121, 1287-1298. doi: 10.1093/aob/mcy017

Kolarcik, V., Kocova, V., and Vaskova, D. (2018). Flow cytometric seed screen data are consistent with models of chromosome inheritance in asymmetrically compensating allopolyploids. Cytometry A 93A, 737-748. doi: 10.1002/cyto.a. 23511

Koltunow, A. M., and Grossniklaus, U. (2003). Apomixis, a developmental perspective. Annu. Rev. Plant Biol. 54, 547-574. doi: 10.1146/annurev.arplant. 54.110901 .160842

Koltunow, A. M., Johnson, S. D., and Bicknell, R. A. (1998). Sexual and apomictic development in Hieracium. Sex. Plant Reprod. 11, 213-230. doi: 10.1007/ s004970050144

Koltunow, A. M., Johnson, S. D., Lynch, M., Yoshihara, T., and Costantino, P. (2001). Expression of rolB in apomictic Hieracium piloselloides Vill. causes ectopic meristems in planta and changes in ovule formation where apomixis initiates at higher frequency. Planta 214, 196-205. doi: 10.1007/s004250100612

Koltunow, A. M. G., Johnson, S. D., Rodrigues, J. C. M., Okada, T., Hu, Y., Tsuchiya, T., et al. (2011). Sexual reproduction is the default mode in apomictic Hieracium subgenus Pilosella, in which two dominant loci function to enable apomixis. Plant J. 66, 890-902. doi: 10.1111/j.1365-313X.2011.04556.x

Krahulcova, A., Krahulec, F., and Rosenbaumova, R. (2011). Expressivity of apomixis in $2 \mathrm{n}+\mathrm{n}$ hybrids from an apomictic and asexual parent: insights into variation detected in Pilosella (Asteraceae: lactuceae). Sex. Plant Reprod. 24, 63-74. doi: 10.1007/s00497-010-0152-x

Krahulcova, A., and Rotreklova, O. (2010). Use of flow cytometry in research on apomictic plants. Preslia 82, 23-39.

Krahulec, F., Krahulcova, A., Rosenbaumova, R., and Plackova, I. (2011). Production of polyhaploids by facultatively apomictic Pilosella can result in the formation of new genotypes via genome doubling. Preslia 83, 471-490.

Kreiner, J. M., Kron, P., and Husband, B. C. (2017). Evolutionary dynamics of unreduced gametes. Trends Genet. 33, 583-593. doi: 10.1016/j.tig.2017.06.009

Laspina, N. V., Vega, T., Seijo, J. G., Gonzalez, A. M., Martelotto, L. G., Stein, J., et al. (2008). Gene expression analysis at the onset of aposporous apomixis in Paspalum notatum. Plant Mol. Biol. 67, 615-628. doi: 10.1007/s11103-0089341-5 
León-Martínez, G., and Vielle-Calzada, J. P. (2019). Apomixis in flowering plants: developmental and evolutionary considerations. Curr. Top. Dev. Biol. 131, 565-604. doi: 10.1016/bs.ctdb.2018.11.014

Li, S., Zhou, B., Peng, X., Kuang, Q., Huang, X., Yao, J., et al. (2014). OsFIE2 plays an essential role in the regulation of rice vegetative and reproductive development. New Phytol. 201, 66-79. doi: 10.1111/nph.12472

Lovell, J. T., Olawale, M. A., Martin, M., Schranz, M. E., Koch, M., Kiefer, C., et al. (2013). On the origin and evolution of apomixis in Boechera. Plant Reprod. 26, 309-315. doi: 10.1007/s00497-013-0218-7

Malaviya, D. R. (1998). Evaluation of Panicum maximum lines for sustained productivity. Range Manag. Agrofor. 19, 126-132.

Marimuthu, M. P., Jolivet, S., Ravi, M., Pereira, L., Davda, J. N., Cromer, L., et al. (2011). Synthetic clonal reproduction through seeds. Science 331:876. doi: $10.1126 /$ science. 1199682

Martinez, E. J., Espinoza, F., and Quarin, C. L. (1994). BIII progeny $(2 n+n)$ from apomictic Papsplum notatum obtained through early pollination. J. Hered. 85, 295-297. doi: 10.1093/oxfordjournals.jhered.a111460

Mason, A. S., and Pires, J. C. (2015). Unreduced gametes: meiotic mishap or evolutionary mechanism? Trends Genet. 31, 5-10. doi: 10.1016/j.tig.2014.09.011

Matzk, F. (1991). A novel approach to differentiated embryos in the absence of endosperm. Sex. Plant Reprod. 4, 88-94. doi: 10.1007/BF00196493

Matzk, F., Meister, A., Brutovska, R., and Schubert, I. (2001). Reconstruction of reproductive diversity in Hypericum perforatum $\mathrm{L}$. opens novel strategies to manage apomixis. Plant J. 26, 275-282. doi: 10.1046/j.1365-313X.2001.01026.x

Matzk, F., Meister, A., and Schubert, I. (2000). An efficient screen for reproductive pathways using mature seeds of monocots and dicots. Plant J. 21, 97-108. doi: 10.1046/j.1365-313x.2000.00647.x

Matzk, F., Prodanovic, S., Baumlein, H., and Schubert, I. (2005). The inheritance of apomixis in Poa pratensis confirms a five- locus model with differences in gene expressivity and penetrance. Plant Cell 17, 13-24. doi: 10.1105/tpc.104.027359

Matzk, F. S., Pradanovic, A., Chizal, J., Tiedemann, F., Arzenton, F., Blattner, J., et al. (2007). "Genetic control of apomixis: preliminary lessons from Poa, Hypericum and wheat egg cells," in Apomixis: Evolution, Mechanisms and Perspectives, eds E. Horandl, U. Grossniklaus, P. van Dijk, and T. F. Sharbel (Rugell: ARG Gantner Verlag), 159-166.

Mecchia, M. A., Ochogavia, A., Selva, J. P., Laspina, N., Felitti, S., Martelloto, L. G., et al. (2007). Genome polymorphisms and gene differential expression in a 'back-and-forth' ploidy altered series of weeping lovegrass (Eragrotis curvula). J. Plant Physiol. 164, 1051-1061. doi: 10.1016/j.jplph.2006.07.002

Mieulet, D., Jovilet, S., Rivard, M., Cromer, L., Vernet, A., Mayonove, P., et al. (2016). Turning rice meiosis into mitosis. Cell Res. 26, 1242-1254. doi: 10.1038/ cr.2016.117

Mirzagadheri, G., and Horandl, E. (2016). The evolution of meiotic sex and its alternatives. Proc. Biol. Sci. 283:1221. doi: 10.1098/rspb.2016. 1221

Muntzing, A., and Muntzing, G. (1943). Spontaneous changes in chromosome number in apomictic species of Potentilla collina. Hereditas 29, 451-460. doi: 10.1111/j.1601-5223.1943.tb03299.x

Nakagawa, H. (1990). Embryo sac analysis and crossing procedure for breeding apomictic guinea grass (Panicum maximum Jacq.). JARQ 24, 163-168.

Nakagawa, H., and Hanna, W. W. (1990). Morphology, origin and cytogenetics of a 48-chromosome Panicum maximum. Cytologia 55, 471-474. doi: 10.1508/ cytologia. 55.471

Nakajima, K., Komatsu, N., Mochizuki, N., and Suzuki, S. (1979). Isolation of diploid and tetraploid sexual plants in guinea grass (Panicum maximum Jacq.). Jpn. J. Breed. 29, 228-238. doi: 10.1270/jsbbs1951.29.228

Nassar, N. M. A. (2006). Chromosome doubling induces apomixis in a cassava x Manihot anomala hybrid. Hereditas 143, 246-248. doi: 10.1111/j.2006.00180661.01957.x

Naumova, T. N., Hayward, M., and Wagenvoort, M. (1999). Apomixis and sexuality in diploid and tetraploid accessions of Brachiaria decumbens. Sex. Plant Reprod. 12, 43-52. doi: 10.1007/s004970050170

Nogler, G. A. (1984a). “Gametophytic apomixis," in Embryology of Angiosperms, ed. B. M. Johri (Berlin: Springer), 475-518.

Nogler, G. A. (1984b). Genetics of apospory in apomictic Ranunculus auricomus V. Conclusion. Bot. Helv. 94, 411-422.

Nogler, G. A. (1994). Genetics of gametophytic apomixis-a historical sketch. Polish Bot. Stud. 8, 5-11.
Nordborg, G. (1967). Embryological studies in the Sanguisorba minor complex (Rosaceae). Bot. Not. 120, 109-119.

Noyes, R. D. (2005). Inheritance of apomeiosis (diplospory) in fleabanes (Erigeron, Asteraceae). Heredity 94, 193-198. doi: 10.1038/sj.hdy.6800597

Noyes, R. D. (2006). Apomixis via recombination in genome regions for apomeiosis (diplospory) and parthenogenesis in Erigeron. Sex. Plant Reprod. 19, 7-18. doi: 10.1007/s00497-005-0017-x

Noyes, R. D., Baker, R., and Mai, B. (2007). Mendelian segregation for two-factor apomixis in Erigeron annuus (Asteraceae). Heredity 98, 92-98. doi: 10.1038/sj. hdy. 6800907

Noyes, R. D., and Rieseberg, L. H. (2000). Two independent loci control agamospermy (apomixis) in the triploid flowering plant Erigeron annus. Genetics 155, 379-390.

Noyes, R. D., and Wagner, J. D. (2014). Dihaploidy yields diploid apomicts and parthenogenesis in Erigeron (Asteraceae). Am. J. Bot. 101, 1-10. doi: 10.3732/ ajb.1400008

Okada, T., Hu, Y., Tucker, M. R., Taylor, J. M., Johnson, S. D., Spriggs, A., et al. (2013). Enlarging cells initiating apomixis in Hieracium praealtum transition to an embryo sac program prior to entering mitosis. Plant Physiol. 163, 216-231. doi: 10.1104/pp.113.219485

Okada, T., Ito, K., Johnson, S. D., Oelkers, K., Suzuki, G., Houben, A., et al. (2011). Chromosomes carrying meiotic avoidance loci in three apomictic eudicot Hieracium subgenus Pilosella species share structural features with two monocot apomicts. Plant Physiol. 157, 1327-1341. doi: 10.1104/pp.111.181164

Ozias-Akins, P., and van Dijk, P. J. (2007). Mendelian genetics of apomixis in plants. Annu. Rev. Genet. 41, 509-537. doi: 10.1146/annurev.genet.40.110405. 090511

Peel, M. D., Carman, J. G., and Leblanc, O. (1997). Megasporocyte callose in apomictic buffelgrass, Kentucy bluegrass, Pennisetum squamulatum Fresen, Tripsacum L. and weeping lovegrass. Crop Sci. 37, 724-732. doi: 10.2135/ cropsci1997.0011183X003700030006x

Polegri, L., Calderini, O., Arcioni, S., and Pupilli, F. (2010). Specific expression of apomixis linked alleles revealed by comparative transcriptomic analysis of sexual and apomictic Paspalum simplex Morong flowers. J. Exp. Bot. 61, 1869-1883. doi: 10.1093/jxb/erq054

Porceddu, A., Albertini, E., Barcaccia, G., Falistocco, E., and Falcinelli, M. (2002). Linkage mapping in apomictic and sexual Kentucky bluegrass (Poa pratensis L.) genotypes using a two-way pseudo test cross strategy based on AFLP and SAMPL markers. Theor. Appl. Genet. 104, 273-280. doi: 10.1007/ s001220100659

Pupilli, F., and Barcaccia, G. (2012). Cloning plants by seeds: inheritance models and candidate genes to increase fundamental knowledge for engineering apomixis in sexual crops. J. Biotechnol. 159, 291-311. doi: 10.1016/j.jbiotec. 2011.08.028

Quarin, C. L., Espinoza, F., Martinez, E. J., Pessino, S. C., and Bovo, O. A. (2001). A rise of ploidy level induces the expression of apomixis in Paspalum notatum. Sex. Plant Reprod. 13, 243-249. doi: 10.1007/s004970100070

Quarin, C. L., and Hanna, W. W. (1980). Effect of three ploidy levels on meiosis and mode of reproduction in Paspalum hexastachyum. Crop Sci. 20, 69-75. doi: 10.2135/cropsci1980.0011183X002000010016x

Radhakrishna, A., Dwivedi, K. K., Srivastava, M. K., Roy, A. K., Malaviya, D. R., and Kaushal, P. (2018). Transcriptomic data of pre-meiotic stage of floret development in apomictic and sexual types of guinea grass (Panicum maximum Jacq.). Data Brief 18, 590-593. doi: 10.1016/j.dib.2018.03.001

Ravi, M., and Chan, S. W. L. (2010). Haploid plants produced by centromeremediated genome elimination. Nature 464, 615-618. doi: 10.1038/nature08842

Roche, D., Hanna, W. W., and Ozias-Akins, P. (2001). Is supernumerary chromatin involved in gametophytic apomixis of polyploid plants? Sex. Plant Reprod. 13, 343-349. doi: 10.1007/s004970100094

Rodrigo, J. M., Zappacosta, D. C., Selva, J. P., Garbus, I., Albertini, E., and Eechenique, V. (2017). Apomixis frequency under stress conditions in weeping lovegrass (Eragrostis curvula). PLoS One 12:e0175852. doi: 10.1371/journal. pone.0175852

Rutishauser, A. (1948). Pseudogamie und polymorphie in der gattung Potentilla. Arch. Julius Stift. 23, 267-283.

Sahu, P. P., Gupta, S., Malaviya, D. R., Roy, A. K., Kaushal, P., and Prasad, M. (2012). Transcriptome analysis of differentially expressed genes during embryo sac development in apomeiotic non-parthenogenetic interspecific hybrid of 
Pennisetum glaucum. Mol. Biotechnol. 51, 262-271. doi: 10.1007/s12033-0119464-9

Sailer, C., Schmid, B., and Grossniklaus, U. (2016). Apomixis allows the transgenerational fixation of phenotypes in hybrid plants. Curr. Biol. 26, 331337. doi: $10.1016 /$ j.cub.2015.12.045

Savidan, Y. (1980). Chromosomal and embryological analyses in sexual Eapomictic hybrids of Panicum maximum Jacq. Theor. Appl. Genet. 57, 153-156. doi: 10. 1007/BF00279706

Savidan, Y. (2000). Apomixis, genetics and breeding. Plant Breed. Rev. 18, 13-85.

Savidan, Y., and Pernes, J. (1982). Diploid-tetraploid-dihaploid cycles and the evolution of Panicum maximum Jacq. Evolution 36, 596-600.

Schallau, A., Arzenton, F., Johnston, A. J., Hahnel, U., Koszegi, D., Blattner, F. R., et al. (2010). Identification and genetic analysis of the APOSPORY locus in Hypericum perforatum L. Plant J. 62, 773-784. doi: 10.1111/j.1365-313X.2010. 04188.x

Schinkel, C. C. F., Kirchheimer, B., Dellinger, A. S., Klatt, S., Winkler, M., Dullinger, S., et al. (2016). Correlations of polyploidy and apomixis with elevation and associated environmental gradients in an alpine plant. AoB Plants 8:plw064. doi: 10.1093/aobpla/plw064

Schinkel, C. C. F., Kirchheimer, B., Dullinger, S., Geelen, D., Storme, N. D., and Horandl, E. (2017). Pathways to polyploidy: indications of a female triploid bridge in the alpine species Ranunculus kuepferi (Ranunculaceae). Plant Syst. Evol. 303, 1093-1108. doi: 10.1007/s00606-017$1435-6$

Schmid, M. W., Schmidt, A., and Grossniklaus, U. (2015). The female gametophyte: an emerging model for cell type-specific systems biology in plant development. Front. Plant Sci. 6:907. doi: 10.3389/fpls.2015.00907

Schmidt, A., Schmid, M. W., and Grossniklaus, U. (2015). Plant germline formation: common concepts and developmental flexibility in sexual and asexual reproduction. Development 142, 229-241. doi: 10.1242/dev.102103

Shah, J. N., Kirioukhova, O., Pawar, P., Tayyab, M., Mateo, J. L., and Johnston, A. J. (2016). Depletion of key meiotic genes and transcriptome-wide abiotic stress reprogramming mark early preparatory events ahead of apomeiotic transition. Front. Plant Sci. 7:1539. doi: 10.3389/fpls.2016.01539

Sharbel, T. F., Voigt, M. L., Corral, J. M., Galla, G., Kumlehn, J., Klukas, C., et al. (2010). Apomictic and sexual ovules of Boechera display heterochronic global gene expression patterns. Plant Cell 22, 655-671. doi: 10.1105/tpc.109.072223

Sharma, M. K., Sharma, R., Cao, P., Jenkins, J., Bartley, L. E., Qualls, M., et al. (2012). A genome-wide survey of switchgrass genome structure and organization. PLoS One 7:e33892. doi: 10.1371/journal.pone.0033892

Siena, L. A., Ortiz, J. P. A., Calderini, O., Paolocci, F., Caceres, M. E., Kaushal, P., et al. (2016). An apomixis-linked ORC3-like pseudogene is associated with silencing of its functional homolog in apomictic Paspalum simplex. J. Exp. Bot. 67, 1965-1978. doi: 10.1093/jxb/erw018

Siena, L. A., Sartor, M. E., Espinoza, F., Quarin, C. L., and Ortiz, J. P. A. (2008). Genetic and embryological evidences of apomixis at the diploid level in Paspalum rufum support recurrent auto- polyploidization in the species. Sex. Plant Reprod. 21, 205-215. doi: 10.1007/s00497-008-0080-1

Silveira, E. D., Guimaraes, L. A., AlencarDusi, D. M., Silva, F. R., Martins, N. F., Carmo Costa, M. M., et al. (2012). Expressed sequence-tag analysis of ovaries of Brachiaria brizantha reveals genes associated with the early steps of embryo sac differentiation of apomictic plants. Plant Cell Rep. 31, 403-416. doi: 10.1007/ s00299-011-1175-y

Sokolov, V. A., Tarakanova, T. K., and Abdyrakhmanova, E. A. (2008). The third international conference on apomixis. Russ. J. Genet. 44, 1367-1375. doi: 10. $1134 /$ S1022795408110203

Sousa, A. C. B., Jungmann, L., Campos, T., Sforca, D. A., Boaventura, L. R., Silva, G. M. B., et al. (2011). Development of microsatellite markers in Guinea grass (Panicum maximum Jacq.) and their transferability to other tropical forage grass species. Plant Breed. 130, 104-108. doi: 10.1111/j.1439-0523.2010. 01779.x

Sukhchain, A. (2010). Breeding guinea grass: a review. Range Manag. Agrofor. 31, 109-115.

Takahara, M., Ebina, E., Morita, R., Kazama, Y., Abe, T., Takamizo, T., et al. (2014). DNA marker analysis revealed that the deletion is relatively small in loss-of-apomixis mutants. RIKEN Accel. Prog. Rep. 47:294.
Takahara, M., Morita, R., Kazama, Y., Abe, T., Takamizo, T., and Nakagawa, H. (2016). Sexual reproduction observed in the loss-of-apomixis mutants of guinea grass induced by heavy-ion beam irradiation. RIKEN Accel. Prog. Rep. 49:260.

Talent, N. (2009). Evolution of gametophytic apomixis in flowering plants: an alternative model from Maloid Rosaceae. Theory Biosci. 128, 121-138. doi: 10.1007/s12064-009-0061-4

Tilquin, A., and Kokko, H. (2016). What does the geography of parthenogenesis teach us about sex? Philos. Trans. R. Soc. Lond. B Biol. Sci. 371:20150538. doi: $10.1098 /$ rstb.2015.0538

Tucker, M. R., Araujo, A. C., Paech, N. A., Hecht, V., Schmidt, E. D., Rossell, J. B., et al. (2003). Sexual and apomictic reproduction in Hieracium subgenus Pilosella are closely inter related developmental pathways. Plant Cell 15, 15241537. doi: $10.1105 /$ tpc. 011742

Tucker, M. R., Paech, N. A., Williemse, M. T. M., and Koltunow, A. M. G. (2001). Dynamics of callose deposition and $\beta$-1, 3-glucanase expression during reproductive events in sexual and apomictic Hieracium. Planta 212, 487-498. doi: $10.1007 /$ s004250000445

van Dijk, P., and Bakx-Schotman, J. (2004). Formation of unreduced megaspores (diplospory) in apomictic dandelions (Taraxacum officinale, s.l.) is controlled by a sex-specific dominant locus. Genetics 166, 483-492. doi: 10.1534/genetics. 166.1.483

van Dijk, P. J., van Baarlen, P., and de Jong, H. (2003). The occurrence of phenotypically complementary apomixis-recombinants in crosses between sexual and apomictic dandelions (Taraxacum officinale). Sex. Plant Reprod. 16, 71-76. doi: 10.1007/s00497-003-0177-5

Vijverberg, K., Van der Hulst, R. G. M., Lindhout, P., and van Dijk, P. J. (2004). A genetic linkage map of the diplosporous chromosomal region in Taraxacum officinale (common dandelion. Asteraceae). Theor. Appl. Genet. 108, 725-732. doi: 10.1007/s00122-003-1474-y

Visser, N. C., and Spies, J. J. (1994). Cytogenetic studies in the genus Tribolium (Poaceae: Danthonieae). II. A report on embryo sac development, with special reference to the occurrence of apomixis in diploid specimens. S. Afr. J. Bot. 60 , 22-26. doi: 10.1016/S0254-6299(16)30655-X

Voigt-Zielinski, M. L., Piwczynski, M., and Sharbel, T. F. (2012). Differential effects of polyploidy and diploidy on fitness of apomictic Boechera. Sex. Plant Reprod. 25, 97-109. doi: 10.1007/s00497-012-0181-8

Worthington, M., Heffelfinger, C., Bernal, D., Quintero, C., Zapata, Y. P., Perez, J. G., et al. (2016). A parthenogenesis gene candidate and evidence for segmental alloployploidy in apomictic Brachiaria decumbens. Genetics 203, 1117-1132. doi: 10.1534/genetics.116.190314

Yamada-Akiyama, H., Akiyama, Y., Ebina, M., Xu, Q., Tsuruta, S., Yazaki, J., et al. (2009). Analysis of expressed sequence tags in apomictic guineagrass (Panicum maximum). J. Plant Physiol. 166, 750-761. doi: 10.1016/j.jplph.2008.10.001

Young, B. A., Sherwood, R. T., and Bashaw, E. C. (1979). Cleared-pistil and thick sectioning techniques for detecting aposporous apomixis in grasses. Can. J. Bot. 57, 1668-1672. doi: 10.1139/b79-204

Zavesky, L., Jarolimova, V., and Stepanek, J. (2007). Apomixis in Taraxacum paludosum (section Palustria, Asteraceae): recombinations of apomixis elements in inter-sectional crosses. Plant Syst. Evol. 265, 147-163. doi: 10.1007/ s00606-007-0518-1

Zhang, J. Y., Lee, Y. C., Torres-Jerez, I., Wang, M., Yin, Y., Chou, W. C., et al. (2013). Development of an integrated transcript sequence database and a gene expression atlas for gene discovery and analysis in switchgrass (Panicum virgatum L.). Plant J. 74, 160-173. doi: 10.1111/tpj.12104

Conflict of Interest Statement: The authors declare that the research was conducted in the absence of any commercial or financial relationships that could be construed as a potential conflict of interest.

Copyright $\odot 2019$ Kaushal, Dwivedi, Radhakrishna, Srivastava, Kumar, Roy and Malaviya. This is an open-access article distributed under the terms of the Creative Commons Attribution License (CC BY). The use, distribution or reproduction in other forums is permitted, provided the original author(s) and the copyright owner(s) are credited and that the original publication in this journal is cited, in accordance with accepted academic practice. No use, distribution or reproduction is permitted which does not comply with these terms. 